\title{
Mortality prediction in intensive care units including premorbid functional status improved performance and internal validity
}

André Moser1,*, Matti Reinikainen², Stephan M. Jakob³, Tuomas Selander, Ville Pettilä5,

${ }^{1}$ CTU Bern, University of Bern, Switzerland

2 Department of Anaesthesiology and Intensive Care, Kuopio University Hospital and University of Eastern Finland, Kuopio, Finland

${ }^{3}$ Department of Intensive Care Medicine, Bern University Hospital, University of Bern, Bern, Switzerland

24 Abstract: 200 words, Main text: 3820 words, Tables: 2, Figures: 4, Supplemental Tables: 3 , 


\section{Highlights}

28

29 - We developed and validated an in-hospital mortality prediction model using 61,224

30 admissions $(6,463$ non-survivors) from an international multicenter cohort study.

31 Among the clinically relevant predictors were age, severity of acute illness and 32 admission type, along with premorbid functional status and diagnoses as modeling variables.

$34-$ We found excellent internal discrimination and calibration properties of the developed prediction model.

36 - We used a proposed framework for interpreting validation and transportability properties of prediction models and concluded that while our model showed good geographic discrimination transportability, other performance measures revealed a moderate to high heterogeneity between hospitals. 
42 Objective: Prognostic models are key for benchmarking intensive care units (ICUs). They 43 require up-to-date predictors and should report transportability properties for reliable 44 predictions. We developed and validated an in-hospital mortality risk prediction model to 45 facilitate benchmarking, quality assurance, and health economics evaluation.

47 Study Design and Setting: We retrieved data from the database of an international (Finland, 48 Estonia, Switzerland) multicenter ICU cohort study from 2015-2017. We used a hierarchical 49 logistic regression model that included age, a modified Simplified Acute Physiology Score-II, 50 admission type, premorbid functional status, and diagnosis as grouping variable. We used pooled and meta-analytic cross-validation approaches to assess temporal and geographical transportability.

54 Results: We included 61,224 patients treated in the ICU (hospital mortality 10.6\%). The developed prediction model had an area under the receiver operating characteristic curve 0.886, 95\% confidence interval (CI) 0.882-0.890; a calibration slope $1.01,95 \% \mathrm{CI}(0.99-1.03)$; a mean calibration $-0.004,95 \%$ CI (-0.035-0.027). While the model showed very good internal validity and geographic discrimination transportability, we found substantial heterogeneity of performance measures between ICUs (I-squared: $53.4 \%$ to $84.7 \%$ ).

60

61 Conclusion: A novel framework evaluating the performance of our prediction model provided 62 key information to judge the validity of our model and its adaptation for future use. 


\section{Keywords}

64 Case mix, in-hospital mortality, intensive care, prediction model, transportability, validation 


\section{What is new?}

66

67 Key findings:

68 Our mortality prediction model—which combined established clinically relevant predictors

69 with premorbid functional status and diagnoses as modeling variables-showed very good

70 internal validity, geographic discrimination and temporal transportability, with a substantial

71 heterogeneity of performance measures between ICUs.

72

73 What does this add to what is known?

74 Premorbid functional status and diagnosis are known predictors of ICU-relevant study outcomes, but are not regularly implemented in established scoring systems. The inclusion of this information showed increased predictive model performance compared to predictions from established risk scoring systems, while showing good internal validation and geographic discrimination transportability.

80 What is the implication and what should change now?

81 To the best of our knowledge, this is one of the first development and validation studies to 82 investigate geographical and temporal transportability properties of an ICU mortality 83 prediction model. Transportability properties are key in the reliable monitoring and 84 benchmarking of ICUs and for their planning. They provide an important piece of information about the model validity in other study populations and settings, and should be quantified

86 in future validation studies of ICU prediction models. 


\section{Abbreviations}

88

89 APACHE: Acute Physiology and Chronic Health Evaluation

90 AUC: area under the curve

91 CI: confidence interval

92 ECOG: Eastern Cooperative Oncology Group

93 FICC: Finnish Intensive Care Consortium

94 ICI: Integrated Calibration Index

95 ICU: intensive care unit

96 LASSO: Least absolute shrinkage and selection operator

97 LOESS: Locally estimated scatterplot smoother

98 PI: Prediction interval

99 ROC: receiver operating characteristic

100 SAPS: Simplified Acute Physiology Score

101 OR: odds ratio

102 WHO: World Health Organization 
105 Scoring systems for prediction of mortality risk are widely used to characterize severity of 106 illness in intensive care unit (ICU) patients in clinical trials, benchmarking, quality assurance, and health economics evaluations [1]. The two most widely used scoring systems-APACHE (acute physiology and chronic health evaluation) [2] and SAPS (simplified acute physiology score) [3]—were introduced in the 1980's and repeatedly updated to preserve and improve their predictive value in response to advances in patient care, therapeutic

111 options with prognostic relevance, and changes in demographics. Despite the updates (the 112 most recent generations are APACHE-IV and SAPS-3 [4-8]) and recalibration, these models

113 may lose their validity over time, and have poor external validity when applied in different

114 health care systems. This may interfere with benchmarking of ICUs, and ultimately impact

115 the decision-making of clinicians, health care providers and regulatory bodies. ICU prediction models developed in study populations from the United Kingdom (ICNARC), Australia and

117 New Zealand (ANZIC) and the Netherlands have been updated to address poor validity and

118 were extended with new clinical predictors like functional status which were strongly

119 associated with the study outcome [9-12].

121 The performance of prediction models depends on their validity and transportability, and 122 can be classified into different frameworks [13-15]. Geographical and temporal transportability indicate performance outside the study population used for the development

124 of the prediction model, e.g., in other hospitals or time periods [14,15]. Lack of transportability, case mix differences, changes in mortality between ICUs and over time, drive the need to recalibrate existing prediction models or to develop new ones $[14,16]$. Reporting their validation and transportability is important to avoid biased outcome predictions and to support the planning of ICU benchmarking programs where new ICUs might be included or a comparison with ICUs outside an existing benchmark system might evolve.

131 The aim of this study is to develop and validate an in-hospital mortality risk prediction model 132 by adding simple indicators of premorbid functional status to established outcome predictors 
133 (age, severity of illness, diagnosis, admission type) in order to quantify the validity and

134 transportability properties of the prediction model and to interpret their impact using a 135 proposed framework for validation [14,15].

\section{Methods}

138 The manuscript has been written in accordance with the transparent reporting of a 139 multivariable prediction model for individual prognosis or diagnosis (TRIPOD) statement [17].

140 The TRIPOD checklist is provided in Supplemental Table 1.

\subsection{Study design and population}

143 We conducted a retrospective multicenter study, with prospectively collected data from the

144 international Finnish Intensive Care Consortium benchmarking database (FICC) that 145 includes ICUs from Finland, Estonia and Switzerland. We used all intensive care admissions 146 of the years 2015-2017. We excluded readmissions, admissions after cardiac surgery, and 147 admissions with care restricted to evaluation for potential organ donation. Cardiac surgery 148 admissions were excluded due to their specific pre- and perioperative risk profiles.

\subsection{Data source}

151 We used data from 2015-2017 in the FICC database. The FICC consists of 22 ICUs in Finland, and the ICUs of one university hospital in Estonia (100\% of university ICU admissions and

$15316 \%$ all ICU admissions in Estonia) and one in Switzerland (33 \% of all university hospital

154 ICU admissions and $11 \%$ of all ICU admissions in Switzerland). All except two ICUs were multidisciplinary.

157 Data related to clinical diagnosis, severity of illness scoring systems, care interventions,

158 physiologic, administrative, and in-hospital mortality are prospectively collected during the 159 ICU and hospital stay into local patient health care records (electronic in Finland and 160 Switzerland, paper in Estonia) [18]. Each admission is validated by trained ICU nurse data 
161 managers or intensivists using logical rules, median filtering and graphic displays to ensure

162 data quality, before transfer to the FICC database.

163

164

\subsection{Ethical approval}

165 The model was developed in conjunction with a health economic analysis, whose study

166 protocol, database contents and data management process were approved by the National

167 Institute of Health and Welfare, Finland (Decision numbers THL/1524/5.05.00/2017 and

168 THL/1173/05.00/2018). According to the regulations in Finland, Estonia, and Switzerland,

169 no ethics committee approval was needed for retrospective use of anonymized data.

170

\section{$171 \quad 2.4$ Study outcomes}

172 Prediction of in-hospital mortality. Data on in-hospital mortality was prospectively collected 173 for each admission from the hospital record.

\subsection{Predictors}

176 Based on the literature and discussions among clinical experts we used the following predictors: age, a modified SAPS-II score which excludes age and admission type (see

178 Supplemental Text 1), surgical vs. non-surgical admission, emergency versus elective admission, diagnosis (APACHE-III diagnoses [19,20], Supplemental Table 2) and functional status based on the WHO ECOG classification [21], with the two best categories combined into one (category 0: Normal functional status or able to perform light work, 1: Light limitations: Unable to work but capable of all selfcare, 2: Moderate limitations: Need for some help in selfcare, 3: Severe limitations: Fully dependent on help).

\subsection{Statistical methods}

186 We describe the study population using frequencies (n), percentages (\%), median and 187 interquartile range (IQR). For the prediction model development we followed the 188 recommendations by Steyerberg and Harrell [22,23]. In brief, Steyerberg and Harrell

189 recommend not to use data-splitting approaches for validation and that heterogeneity of 
190 performance measures should be assessed. We used hierarchical multivariable logistic 191 regression models accounting for nested admissions within APACHE-III diagnostic groups to 192 develop the prediction model $\left(\mathrm{M}_{\text {developed }}\right)$. A second prediction model excluded premorbid 193 functional status as predictor $\left(\mathrm{M}_{\text {developed } 2}\right)$. We modeled the continuous variables age and 194 modified SAPS-II score as restricted cubic splines with 3 knots chosen at the 10th, 50th and 195 90th percentiles [13,24]. A priori we included an interaction effect between age and the 196 modified SAPS-II score. We report predictor effects as odds ratios (OR) with 95\% confidence 197 intervals (CI). We assessed the overall association of variables and model fit using $\chi^{2}(\mathrm{k})$ 198 statistics with $\mathrm{k}$ degrees of freedom from a deviance test. For parsimony of the risk score, we set varying intercept estimates for APACHE-III diagnoses to zero if the $95 \%$ CI overlapped by an OR of 1 . We calculated the probability of hospital death from the original SAPS-II score to compare predictions from derived models [4]. We assessed discrimination ability with the area under the receiver operating characteristics curve (AUC), mean calibration (calibration-inthe-large), weak calibration (calibration slope) and moderate calibration performance using a fitted calibration curve from locally estimated scatterplot smoother (LOESS), the Integrated Calibration Index (ICI), the maximum, median and $90^{\text {th }}$ percentile of the absolute difference between the LOESS calibration and the diagonal line (Emax, E50, E90), and the Brier score [25-27]. We used a second-degree polynomial with a smoothing parameter set to 0.75 for LOESS. We used a modified large sample Hosmer-Lemeshow test, which was devised from a model attaining a p-value of the traditional Hosmer-Lemeshow test of 0.05 in a sample of one

210 million observations [28]. We used a bootstrap approach for internal model validation based 211 on 100 replicates $[13,24]$. We assessed temporal and/or geographical transportability, that 212 is, to what extent predictions perform as well in other study populations (in time and/or at 213 different hospitals) and used a proposed framework for interpretation [13,14]. For that 214 purpose, we defined two time periods: Time period one covers the years 2015-2016, whereas time period two covers the year 2017.

217 In brief, we first assessed to what extent the development and validation samples were related 218 (i.e., to what extent case mix differed between hospitals and time periods). For that purpose, 219 we derived AUC from hierarchical logistic membership models (including the predictors used 
220 for the mortality prediction model and the outcome variable) and reported standardized 221 standard deviations (SDs) of linear predictors (i.e., SDs from validation samples are divided

222 by the SD of the development sample) [14]. Development and validation samples were defined 223 by a "leave-one-unit-out" or a "leave-one-period-out" approach ('internal-external' validation) 224 [15]. Each model performance measure is estimated from the left-out validation samples. We 225 reported pooled estimates and estimates from random effects meta-analyses of AUC and calibration performance measures with 95\% CI and prediction intervals (PI) [15]. Results from the meta-analyses include DerSimonian-Laird estimators for between-study standard deviation, I-squared and Cochran's Q-statistic for heterogeneity. Because of the small number of time periods no meta-analytic approach was used for assessing temporal transportability.

232 We performed several sensitivity analyses. First, we derived a prediction model which used the same predictors as $\mathrm{M}_{\text {developed }}$ but did not account for APACHE-III diagnosis groups

$234\left(\mathrm{M}_{\text {sensitivity }}\right)$, by using an ordinary logistic regression model. We compared $\mathrm{M}_{\text {developed }}$ with

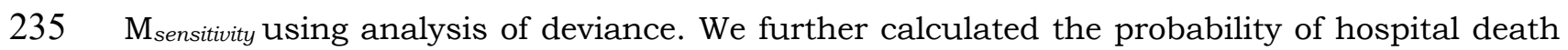
236 from $\mathrm{M}_{\text {developed }}, \mathrm{M}_{\text {developed2 }}$ (same as $\mathrm{M}_{\text {developed }}$ but without predictor premorbid functional status),

$237 \mathrm{M}_{\text {sensitivity, }}$ and the original SAPS-II score, and plotted receiver operating characteristic curves. Second, we used (non-hierarchical) ordinary and penalized logistic regression and least absolute shrinkage and selection operator (LASSO) with APACHE-III diagnostic groups as fixed effects. Penalized estimates were optimized with a modified Akaike Information Criterion

241 [24]. The minimum penalizing factor for LASSO was derived from 30 cross-validation samples.

242 Third, we compared discrimination and calibration performance of the shrunken risk score 243 with its non-shrunken version, that is, when the varying intercept estimates of APACHE-III 244 diagnoses were not set to zero. All analyses were complete case analyses and excluded 245 patients with missing predictor information and were performed in $\mathrm{R}$ version 4.0.2. 
250 The eligible study population included 61,385 patients. We excluded 161 patients $(0.3 \%)$

251 because of missing values in age $(n=14)$, admission type $(n=126)$, SAPS-II score $(n=15)$ and

252 APACHE-III diagnosis $(n=6)$. Thus, the final analysis included 61,224 patients with 6,463

253 (10.6\%) in-hospital deaths (Table 1). The median age was 63 years (IQR 24), the median SAPS-

254 II score was 31 points (IQR 22) and the median modified SAPS-II was 15 points (IQR 19) and

$25540 \%$ were female. Eighty percent of the admissions were emergency admissions and $40 \%$

256 were surgical. Around 30\% of all patients had a premorbid functional limitation. The number

257 of admissions and number of deaths per each unit and year is shown in Supplemental Table

$258 \underline{3}$.

259

260

3.2 Prediction model

261 The prediction model ( $\mathrm{M}_{\text {developed }}$ ) developed for the risk score included 5 variables (age,

262 modified SAPS-II score, admission type, premorbid functional status and APACHE-III diagnostic group) with 15 parameters (1 parameter for intercept, 2 parameters for non-linear age, 2 parameters for non-linear modified SAPS-II score, 4 parameters for interaction effect, 2 parameters for admission type (surgical, emergency), 3 parameters for functional status, 1 parameter for APACHE-III diagnoses grouping variable). Figure 1 shows the joint predictor effects of the categorical variables from the hierarchical logistic regression model. Surgical patients had lower odds of dying than non-surgical patients [OR 0.79, 95\%CI (0.64-0.98)]; emergency admissions had higher odds of dying than elective admissions [OR $2.85,95 \% \mathrm{CI}$ (2.36-3.45)]. Patients with premorbid functional limitations showed higher odds of dying than patients with normal premorbid functional status. Premorbid functional status was strongly associated with mortality (deviance $\left(\mathrm{M}_{\text {developed }}\right)=27891, \quad$ deviance $\left(\mathrm{M}_{\text {developed2 }}\right)=28052$; $\left.\chi^{2}(3)=161.0, p<0.001\right)$. Age and the modified SAPS-II score showed strong evidence for a non-

274 linear relationship (for age: $\chi^{2}(1)=8.07, p=0.004$; for modified SAPS-II score $\chi^{2}(1)=86.18$, $\mathrm{p}<0.001$; Figure 2). There was strong evidence for an interaction effect of the non-linear modeled variables $\left(\chi^{2}(4)=67.22, \mathrm{p}<0.001\right)$. Figure 3 shows the varying intercept estimates for the APACHE-III diagnoses. The estimated between-diagnoses standard deviation was 0.63; that is, $95 \%$ of the ORs of the APACHE-III diagnosis estimates lie between 0.29 (2.5\% OR) and $3.43(97.5 \%$ OR). Estimates with 95\% CIs overlapping an OR of 1 are shown in red. These 
estimates were set to zero in the final risk score for model parsimony. APACHE-III code $=0$

281 covers "other postoperative" admissions ( $\mathrm{n}=560,61 \%$ various emergencies). Due to the

282 clinical heterogeneity, their estimate was also set to zero. The final prediction model includes

28340 APACHE-III diagnoses (calculation formula in Supplemental Text 2). Supplemental Figure

$284 \quad 1$ and Supplemental Figure 2 show crude predictor effects. The effect of emergency

285 admissions decreases from a crude model [OR=5.97, 95\%CI (5.01-7.10)] to OR=2.85 (reported

286 above) in an adjusted model.

287

288

\subsection{Discrimination and calibration}

289 Figure 4 shows the internal discrimination and calibration properties of the developed model 290 (M $\left.\mathrm{M}_{\text {developed }}\right)$ : AUC 0.886, 95\%CI (0.882-0.890), mean calibration -0.004, 95\%CI (-0.035-0.027), 291 calibration slope 1.01, 95\%CI (0.99-1.03), ICI 0.134, E50 0.032, E90 0.463, Emax 1.000 and a Brier score 0.067. The Hosmer-Lemeshow test for large samples resulted in $p=0.05$. The

293 prediction model without the predictor premorbid functional (M $\mathrm{M}_{\text {developed2) had }}$ an AUC 0.885, 95\%CI (0.881-0.889), mean calibration 0.001 (-0.030-0.031) and calibration slope 1.01, 95\%CI (0.99-1.03). Predictions from the original SAPS-II score revealed only slightly lower discrimination ability [AUC=0.864, 95\%CI (0.860-0.869)], but poor calibration (Supplemental Figure 3). Supplemental Figure 4 shows receiver operating characteristic curves from mortality predictions from $\mathrm{M}_{\text {developed, }} \mathrm{M}_{\text {developed2, }} M_{\text {sensitivity }}$ and from the original SAPS-II score. Discrimination ability was best for the developed prediction model.

\subsection{Validation and interpretation}

302 We assessed the relevance of case mix differences. Supplemental Figure 5 shows AUC estimates from membership models. For geographical validation samples, AUC ranged from 0.65 to 0.96 , indicating a substantial heterogeneity between the development and validation samples. Two units with AUC>0.9 are specialized ICUs. The development and validation samples between time periods were similar in terms of the used predictor variables and the outcome (AUC=0.54). Supplemental Figures 6 shows results from standardized SDs of linear 
309 hospitals. The interpretation of results from linear predictors are comparable to the ones from

310 membership models. One hospital was left out of the membership modelling and the

311 geographical transportability assessment because of a low number of admissions $(n=14)$.

312

313 Table 2 shows results from internal and internal-external validation and transportability

314 investigations. We observed very good internal model reproducibility (for example, AUC from

315 the bootstrap samples was 0.888 compared to 0.886 from the development sample). While

316 the overall internal-external calibration was very good, with 95\% CIs and PIs overlapping a

317 calibration slope of 1 or a mean calibration value of 0 for all validation approaches (except for

318 the pooled geographical-temporal calibration slope, which was $0.978,95 \%$ CI [0.963-0.993]),

319 we found a moderate to high heterogeneity between ICUs for AUC, calibration slope and mean

320 calibration (I-squared ranging from 53.4\%-84.7\%). Supplemental Figures 7-15 show the in-

321 depth results for transportability based on pooled estimates and random-effects meta-

322 analyses.

323

$324 \quad 3.5$ Sensitivity analyses

325 In the sensitivity analyses, we compared $\mathrm{M}_{\text {developed }}$ with a prediction model $\left(\mathrm{M}_{\text {sensitivity }}\right)$ which

326 did not account for APACHE-III diagnosis groups but used the same predictors as model

$327 \mathrm{M}_{\text {developed. }} \mathrm{M}_{\text {sensitivity }}$ is an ordinary logistic regression model with 14 parameters. We found

328 evidence for a better model fit of $\mathrm{M}_{\text {developed }}$ compared to $\mathrm{M}_{\text {sensitivity }}$ (deviance $\left(\mathrm{M}_{\text {developed }}\right)=27,891$,

329 deviance $\left.\left(M_{\text {sensitivit }}\right)=28,864 ; \quad \chi^{2}(1)=973.3, \quad \mathrm{p}<0.001\right) . \quad \underline{\text { Supplemental }}$ Figure 16 and

330 Supplemental Figure 17 show the sensitivity analysis results from different modeling

331 strategies. In general, effect estimates from the investigated model approaches were similar.

332 Supplemental Figure 18 shows the discrimination and calibration properties of the non-

333 shrunken model; that is, when the estimated varying intercepts of the APACHE-III diagnosis

334 groups were not set to zero. The results were similar to the implemented risk score from

$335 \mathrm{M}_{\text {developed. }}$

337 4. Discussion 
339 Based on data of 61,224 patients in a large international multicenter ICU database, we 340 created a new in-hospital mortality prediction model by adding premorbid functional status 341 to well-established predictors of in-hospital mortality (age, severity of acute illness, diagnosis, 342 admission type). Premorbid functional status was strongly associated with mortality and 343 increased the predictive performance of the model, while the inclusion of diagnosis accounted 344 for the large heterogeneity between diagnosis groups. Overall, the prediction model showed 345 excellent discrimination and calibration performance. We used a proposed framework for 346 interpreting validation results which investigated case-mix differences and transportability 347 properties. We concluded that while a large heterogeneity between ICUs due to case-mix 348 differences exists our prediction model might provide reliable predictions for future monitoring and benchmarking of key performance indicators.

351 Valid mortality predictions are essential for use of standardized mortality ratios (SMRs) to assess ICU performance, both for within-ICU evolution and for comparisons between ICUs in benchmarking programs $[29,30]$. However their use has been criticized for susceptibility to case-mix differences [1]. By using different analyses approaches (membership model approach and internal-external validation) we found substantial differences in case mix among hospitals in our study population. While our findings from internal validation and cross-validated pooled estimates showed very good discrimination and calibration properties, we found a moderate to high variation of prediction model performance measures between ICUs using meta-analytic approaches. Predictions intervals from meta-analytic approaches

360 (that is, the uncertainty interval in which a performance measure of a potentially new ICU will be expected to lie) indicated that the discriminative ability was very good (lowest lower

362 95\% PI: 0.85), while the prediction uncertainties of the mean calibration and calibration slope 363 indicated a potentially not optimal performing prediction model for new ICUs. Heterogeneity 364 between ICUs was mostly expected, given that our data includes admissions from different hospital categories and from different health care systems, and can be explained by difference

366 in case-mix, in resource use or in quality of care. Our joint geographical-temporal transportability results require a careful interpretation because they are prone to potential 
model overfitting and biased performance measures because of the small event size of certain

369 hospitals using only admissions from the year 2017 for validation.

371 The 'customization', modernization, and development of new prediction models should offer clear benefits [16,31-34]. The inclusion of diagnoses should help cluster patients into homogenous groups, with similar treatment procedures, resource utilization and patient outcomes $[9,35,36]$. Nevertheless, it is conceivable that the premorbid functional status may have a relevant impact on risk of in-hospital death and consequently on the performance of mortality prediction models [12,34,37]. Approximately $30 \%$ of our study patients had premorbid functional limitation, which was strongly associated with mortality. FerrandoVivas et al. found that including the level of assistance needed in daily activities (none, some, total) improved the predictive performance of the ICNARC model [12]. The more detailed WHO ECOG classification we used also improved the performance, emphasizing the need to include premorbid functional status in ICU scoring systems. Demographic changes with an increasing proportion of older people will likely increase the ICU admissions of elderly. Muscedere et al. showed in a systematic review that frailty is an important factor of mortality in elderly treated in the ICU [38]. Dólera-Moreno et al. developed and validated a risk prediction model which uses frailty measures as predictors for all-cause mortality [34]. The implementation of geriatric assessments in ICUs might foster the use of clinical relevant predictors relevant for older persons in future prediction models [39-41].

The statistical approach used for the development and validation of a prediction model should

390 be critically addressed [13]. Due to the a priori decision to include diagnoses, we used a

391 hierarchical regression model to account for grouping of intensive care admissions and

392 discussed its advantages and disadvantages with clinical experts and statisticians [42]. The

393 multicenter study design allowed in-depth validation of the developed risk model and we used

394 the framework proposed by Debray et al. as a guide in interpreting our validation results

$395[14,15]$. The internal, geographical, and temporal transportability validation methods provide

396 important key measures for validity and for generalizability for broader study populations.

397 Austin et al. used different admission eligibility criteria for different time periods to assess 
temporal and methodological portability [15]. Changes in the structural composition of ICUs

399 in a benchmarking program (for example by the inclusion of specialized ICUs) inherently serve

400 as a new set of admissions of an ICU which allows for the investigation of transportability

401 properties. The FICC, for example, was extended by a neurosurgical ICU in 2017 and was

402 included in the geographical transportability investigation. Our findings from the

403 membership model and the used internal-external validation approaches will be included in

404 regular reports of the FICC benchmarking program and might support the future planning of

405 this program. Further, with the interpretation of measures of heterogeneity from the

406 membership model or the used internal-external validation approaches we have a tool which

407 supports the decision whether a recalibration of the prediction model might be required [14].

408

$409 \quad 4.1$ Strengths

410 First, the large sample size from different hospitals, years, and health care systems, and use

411 of advanced statistical approaches, allows an in-depth investigation of the heterogeneity of

412 performance measures and should enhance the generalizability of the model. For the

413 validation of prediction models an event size of at least 100 events have been recommended

$414[22,43]$. Most hospitals in our data have a larger event size when data is combined for all

415 years (i.e., for the assessment of geographical transportability). Second, data validation by

416 trained data managers, use of logical rules, median filtering, and graphic displays should

417 enhance data quality. Third, the FICC cohort study collects relevant patient and clinical

418 information which allows almost unbiased predictions, by using appropriate predictor and

419 grouping information.

420

421

\subsection{Limitations}

422 All prediction models tend to deteriorate over time as medical care evolves, demographics

423 change, and new diseases appear. Although our model was stable over the recent three years,

424 its predictive ability is likely to change over time. Therefore, regular evaluation of the

425 predictive value of the model should be foreseen and recalibration performed as necessary.

426 The methodology we used will facilitate such a recalibration. Further, future prediction

427 models for intensive care could be improved by using quality of life measures and other study 
endpoints or hospital information (like, hospital category, staffing information or hospital volume) to possibly improve the performance and transportability of the prediction model for

430 benchmarking programs [16,31]. Such information was not used for the prediction model 431 development.

\subsection{Implications}

434 Our study has important implications for clinicians, health care providers, and health system evaluations. First, the inclusion of premorbid functional status in addition to established clinical predictors in our prediction model improved the performance of the prediction model. Second, the quantification of validation and transportability properties provides important information for future benchmarking programs. As proposed by Debray et al. [14], we encourage in the development of future ICU prediction models to report the transportability properties due to their relevance to changes in case mix, advances in medical technologies or changes in mortality. Third, this modeling strategy might help clinicians, health care providers, guideline developers and regulatory bodies to enhance evaluation of ICU care and finally to improve population health.

\subsection{Conclusions}

446 Premorbid functional status is an important predictor of hospital outcome and improved the 447 predictive performance of our prediction model. Our model showed very good internal validity but a substantial heterogeneity of performance measures between ICUs, providing key information to judge the validity of our model and its adaptation for future use. We used a proposed framework for interpreting model validation findings, which proved helpful in the process of validating our prediction model. We encourage clinicians, health care providers, guideline developers and health service researchers to carefully address the multidimensional aspects of developing ICU prediction models. This includes discussions about the selection of relevant predictors, the interpretation of statistical findings and approaches used, as well as the reporting of key indicators to interpret the model performance and the potential consequences, like transportability to other study settings. We believe that a structured 

model in selected settings. 
461 AM: Conceptualization, Methodology, Software, Validation, Formal analysis, Writing -

462 Original Draft, Visualization

463 MR: Conceptualization, Methodology, Writing - Review \& Editing

464 SJ: Conceptualization, Methodology, Resources, Writing - Review \& Editing

465 TS: Conceptualization, Methodology, Writing - Review \& Editing

466 VP: Conceptualization, Methodology, Writing - Review \& Editing

467 OK: Conceptualization, Methodology, Writing - Review \& Editing

468 TV: Conceptualization, Methodology, Writing - Review \& Editing

469 RR: Investigation, Resources, Data Curation, Writing - Review \& Editing, Supervision, Project

470 administration

471 JT: Conceptualization, Methodology, Investigation, Resources, Data Curation, Writing -

472 Review \& Editing, Visualization, Supervision, Project administration

473

\section{Conflicts of interest}

475 Dr. Moser has no conflicts of interest.

476 Dr. Reinikainen has no conflicts of interest.

477 Dr. Jakob: The Department of Intensive Care Medicine, University Hospital Bern, has, or

478 has had in the past, research \& development/consulting contracts with Edwards

479 Lifesciences Services GmbH, Phagenesis Limited and Nestlé. The money was paid into a

480 departmental fund, and Dr. S. Jakob did not receive any financial gain. The Department of

481 Intensive Care Medicine, University Hospital Bern, has received in the past unrestricted

482 educational grants from the following organizations for organizing bi-annual postgraduate

483 courses in the fields of critical care ultrasound, management of ECMO and mechanical

484 ventilation: Pierre Fabre Pharma AG (formerly known as RobaPharm), Pfizer AG, Bard

485 Medica S.A., Abbott AG, Anandic Medical Systems, PanGas AG Healthcare, Orion Pharma,

486 Bracco, Edwards Lifesciences AG, Hamilton Medical AG, Fresenius Kabi (Schweiz) AG,

487 Getinge Group Maquet AG, Dräger Schweiz AG, Teleflex Medical GmbH.

488 Mr. Selander has no conflicts of interest.

489 Dr. Pettilä has no conflicts of interest. 
Mr. Kiiski has no conflicts of interest.

491 Dr. Varpula has no conflicts of interest.

492 Dr. Raj has no conflicts of interest.

493 Dr. Takala has no conflicts of interest.

494

495

Availability of data statement

496 The study authors had the permission from FINDATA (Social and Health Data Permit

497 Authority) to analyze the data. A secondary use of the data for other researchers can be 498 obtained through FINDATA (https://findata.fi/en/) according to the Finish Secondary Data 499 Act.

500

501

Acknowledgments

502 We thank Dr. Andreas Limacher for his helpful comments on the statistical analysis and 503 methodology.

504

505

Funding

506

Dr. Raj has received research grants from Finska Läkaresällskapet, Svenska Kulturfonden and Medicinska Understödsföreningen Liv \& Hälsa.

\section{References}

510

511 [1] Salluh JIF, Soares M, Keegan MT. Understanding intensive care unit benchmarking. Intensive Care Med 2017;43:1703-7. https://doi.org/10.1007/s00134-017-4760-x.

513 [2] Knaus WA, Zimmerman JE, Wagner DP, Draper EA, Lawrence DE. APACHE-acute physiology and chronic health evaluation: a physiologically based classification system. Crit Care Med 1981;9:591-7. https://doi.org/10.1097/00003246198108000-00008. simplified acute physiology score for ICU patients. Crit Care Med 1984;12:975-7. 
520 [4] Le Gall JR. A new Simplified Acute Physiology Score (SAPS II) based on a European/North American multicenter study. JAMA J Am Med Assoc 1993;270:2957-63. https://doi.org/10.1001/jama.270.24.2957.

[5] Metnitz PGH, Moreno RP, Almeida E, Jordan B, Bauer P, Campos RA, et al. SAPS 3-

[6] Moreno RP, Metnitz PGH, Almeida E, Jordan B, Bauer P, Campos RA, et al. SAPS 3From evaluation of the patient to evaluation of the intensive care unit. Part 1:

[8] Knaus WA, Draper EA, Wagner DP, Zimmerman JE. APACHE II: a severity of disease classification system. Crit Care Med 1985;13:818-29.

[9] Harrison DA, Parry GJ, Carpenter JR, Short A, Rowan K. A new risk prediction model Objectives, methods and cohort description. Intensive Care Med 2005;31:1336-44. https://doi.org/10.1007/s00134-005-2762-6. From evaluation of the patient to evaluation of the intensive care unit. Part 2: Development of a prognostic model for hospital mortality at ICU admission. Intensive Care Med 2005;31:1345-55. https://doi.org/10.1007/s00134-005-2763-5.

Zimmerman JE, Kramer AA, McNair DS, Malila FM. Acute Physiology and Chronic Health Evaluation (APACHE) IV: Hospital mortality assessment for today's critically ill patients*. Crit Care Med 2006;34:1297-310. https://doi.org/10.1097/01.CCM.0000215112.84523.FO.

541 [10] Paul E, Bailey M, Pilcher D. Risk prediction of hospital mortality for adult patients admitted to Australian and New Zealand intensive care units: Development and validation of the Australian and New Zealand Risk of Death model. J Crit Care 2013;28:935-41. https://doi.org/10.1016/j.jcrc.2013.07.058. 
545 [11] Brinkman S, Bakhshi-Raiez F, Abu-Hanna A, de Jonge E, Bosman RJ, Peelen L, et al. External validation of Acute Physiology and Chronic Health Evaluation IV in Dutch intensive care units and comparison with Acute Physiology and Chronic Health Evaluation II and Simplified Acute Physiology Score II. J Crit Care 2011;26:105.e11-105.e18. https://doi.org/10.1016/j.jcrc.2010.07.007.

[12] Ferrando-Vivas P, Jones A, Rowan KM, Harrison DA. Development and validation of the new ICNARC model for prediction of acute hospital mortality in adult critical

[13] Steyerberg EW. Clinical Prediction Models. New York, NY: Springer New York; 2009. https://doi.org/10.1007/978-0-387-77244-8.

[14] Debray TPA, Vergouwe Y, Koffijberg H, Nieboer D, Steyerberg EW, Moons KGM. A

[15] Austin PC, van Klaveren D, Vergouwe Y, Nieboer D, Lee DS, Steyerberg EW.

[17] Collins GS, Reitsma JB, Altman DG, Moons KGM. Transparent reporting of a multivariable prediction model for individual prognosis or diagnosis (TRIPOD): the TRIPOD statement. BMJ 2015;350:g7594-g7594. https://doi.org/10.1136/bmj.g7594.

[18] Reinikainen M, Mussalo P, Hovilehto S, Uusaro A, Varpula T, Kari A, et al. Association of automated data collection and data completeness with outcomes of intensive care. A new customised model for outcome prediction. Acta Anaesthesiol 
573 [19] Zimmerman JE, Wagner DP, Draper EA, Wright L, Alzola C, Knaus WA. Evaluation of Acute Physiology and Chronic Health Evaluation III predictions of hospital mortality in an independent database. Crit Care Med 1998;26:1317-26. https://doi.org/10.1097/00003246-199808000-00012.

[20] Knaus WA, Wagner DP, Draper EA, Zimmerman JE, Bergner M, Bastos PG, et al. The APACHE III Prognostic System. Chest 1991;100:1619-36. https://doi.org/10.1378/chest.100.6.1619.

[21] Oken MM, Creech RH, Tormey DC, Horton J, Davis TE, McFadden ET, et al. Toxicity and response criteria of the Eastern Cooperative Oncology Group. Am J Clin Oncol 1982;5:649-55.

[22] Steyerberg EW. Validation in prediction research: the waste by data splitting. J Clin Epidemiol 2018;103:131-3. https://doi.org/10.1016/j.jclinepi.2018.07.010.

[23] Steyerberg EW, Harrell FE. Prediction models need appropriate internal, internalexternal, and external validation. J Clin Epidemiol 2016;69:245-7. https://doi.org/10.1016/j.jclinepi.2015.04.005.

[24] Harrell , FE. Regression Modeling Strategies. Cham: Springer International Publishing; 2015. https://doi.org/10.1007/978-3-319-19425-7.

[25] Van Calster B, Nieboer D, Vergouwe Y, De Cock B, Pencina MJ, Steyerberg EW. A calibration hierarchy for risk models was defined: from utopia to empirical data. J Clin Epidemiol 2016;74:167-76. https://doi.org/10.1016/j.jclinepi.2015.12.005.

[26] Austin PC, Steyerberg EW. The Integrated Calibration Index (ICI) and related metrics for quantifying the calibration of logistic regression models. Stat Med 2019;38:405165. https://doi.org/10.1002/sim.8281.

[27] Steyerberg EW, Vickers AJ, Cook NR, Gerds T, Gonen M, Obuchowski N, et al. Assessing the Performance of Prediction Models. Epidemiology 2010;21:128-38. 
https://doi.org/10.1097/EDE.0b013e3181c30fb2.

599 [28] Nattino G, Pennell ML, Lemeshow S. Assessing the goodness of fit of logistic

600

601 regression models in large samples: A modification of the Hosmer-Lemeshow test. Biometrics 2020;76:549-60. https://doi.org/10.1111/biom.13249.

602

[29] Tambeur W, Stijnen P, Vanden Boer G, Maertens P, Weltens C, Rademakers F, et al. 603

604 Standardised mortality ratios as a user-friendly performance metric and trigger for

[30] Verburg IWM, de Jonge E, Peek N, de Keizer NF. The association between outcomebased quality indicators for intensive care units. PLoS One 2018;13:e0198522.

[31] Glance LG, Szalados JE. Benchmarking in Critical Care. Chest 2002;121:326-8. https://doi.org/10.1378/chest.121.2.326.

[32] Metnitz PGH, Lang T, Vesely H, Valentin A, Le Gall JR. Ratios of observed to expected mortality are affected by differences in case mix and quality of care. Intensive Care Med 2000;26:1466-72. https://doi.org/10.1007/s001340000638.

[33] Kramer AA, Zimmerman JE, Knaus WA. Severity of Illness and Predictive Models in Society of Critical Care Medicine's First 50 Years: A Tale of Concord and Conflict. Crit

[34] Dólera-Moreno C, Palazón-Bru A, Colomina-Climent F, Gil-Guillén VF. Construction and internal validation of a new mortality risk score for patients admitted to the intensive care unit. Int J Clin Pract 2016;70:916-22. https://doi.org/10.1111/ijcp.12851.

[35] de Keizer NF, Bonsel GJ, Goldfad C, Rowan KM. The added value that increasing levels of diagnostic information provide in prognostic models to estimate hospital mortality for adult intensive care patients. Intensive Care Med 2000;26:577-84. 
https://doi.org/10.1007/s001340051207.

625 [36] Austin PC, van Walraven C, Wodchis WP, Newman A, Anderson GM. Using the Johns

[37] Krinsley JS, Wasser T, Kang G, Bagshaw SM. Pre-admission functional status

630 impacts the performance of the APACHE IV model of mortality prediction in critically ill patients. Crit Care 2017;21:110. https://doi.org/10.1186/s13054-017-1688-z.

[38] Muscedere J, Waters B, Varambally A, Bagshaw SM, Boyd JG, Maslove D, et al. The impact of frailty on intensive care unit outcomes: a systematic review and metaanalysis. Intensive Care Med 2017;43:1105-22. https://doi.org/10.1007/s00134017-4867-0.

[39] Kerminen H, Huhtala H, Jäntti P, Valvanne J, Jämsen E. Frailty Index and functional level upon admission predict hospital outcomes: an interRAI-based cohort the Frailty Index in hospitalized older patients: Results from the REPOSI register. Eur J Intern Med 2018;56:11-8. https://doi.org/10.1016/j.ejim.2018.06.001.

[41] Evans SJ, Sayers M, Mitnitski A, Rockwood K. The risk of adverse outcomes in hospitalized older patients in relation to a frailty index based on a comprehensive Prediction models for clustered data: comparison of a random intercept and standard regression model. BMC Med Res Methodol 2013;13:19. https://doi.org/10.1186/1471-2288-13-19. 
651 [43] Collins GS, Ogundimu EO, Altman DG. Sample size considerations for the external 652 validation of a multivariable prognostic model: a resampling study. Stat Med $653 \quad 2016 ; 35: 214-26$. https://doi.org/10.1002/sim.6787.

654 
Table 1: Patient characteristics.

Characteristic 2015

2016

2017

All years

\begin{tabular}{|c|c|c|c|c|}
\hline & n/Median (\%/IQR) & $\mathrm{n} /$ Median (\%/IQR) & $\mathrm{n} /$ Median (\%/IQR) & $\mathrm{n} /$ Median (\%/IQR) \\
\hline Age (years) & $63(24)$ & $63(24)$ & $64(23)$ & $63(24)$ \\
\hline Gender (male) & $11882(60)$ & $12,335(60)$ & $12,757(61)$ & $36,974(60)$ \\
\hline SAPS-II score & $31(22)$ & $31(23)$ & $31(22)$ & $31(22)$ \\
\hline $\begin{array}{r}\text { Modified SAPS-II } \\
\text { score }\end{array}$ & $15(20)$ & $15(20)$ & $15(19)$ & $15(19)$ \\
\hline Surgical admission & $7,931(40)$ & $7,880(39)$ & $8,460(40)$ & $24,271(40)$ \\
\hline $\begin{array}{l}\text { Emergency } \\
\text { admission }\end{array}$ & $15,730(80)$ & $16,365(80)$ & $16,643(79)$ & $48,738(80)$ \\
\hline \multicolumn{5}{|l|}{ Functional status } \\
\hline Normal & $14,128(72)$ & $14,650(72)$ & $15,002(71)$ & $43,780(72)$ \\
\hline Light limitation & $3,484(18)$ & $3,656(18)$ & $3,803(18)$ & $10,943(18)$ \\
\hline $\begin{array}{l}\text { Moderate } \\
\text { limitation }\end{array}$ & $1,609(8)$ & $1,667(8)$ & $1,695(8)$ & $4,971(8)$ \\
\hline Severe limitation & $521(3)$ & $502(3)$ & $507(2)$ & $1,530(3)$ \\
\hline Non-survivor & $2,094(11)$ & $2,156(11)$ & $2,213(11)$ & $6,463(11)$ \\
\hline
\end{tabular}

656 Abbreviations: IQR Interquartile range 
Table 2: Validation and transportability properties.

\begin{tabular}{|c|c|c|c|c|}
\hline Measure & Validation & Transportability & Overall estimate $\left(95 \% \mathrm{CI} / \mathrm{PI}^{*}\right)$ & I-squared $(95 \% \mathrm{CI})$ \\
\hline \multirow[t]{7}{*}{ AUC } & Internal: Bootstrap ${ }^{* *}$ & Reproducibility & $0.888(0.884-0.892)$ & \\
\hline & Internal-external: Pooled & Geographical & $0.884(0.880-0.887)$ & \\
\hline & Internal-external: Meta-analysis* & Geographical & $0.881(0.847-0.914)$ & $70.8 \%(55.5 \%-80.9 \%)$ \\
\hline & Internal-external: Pooled & Temporal & $0.886(0.879-0.893)$ & \\
\hline & Internal-external: Meta-analysis* & Temporal & Not reported & Not reported \\
\hline & Internal-external: Pooled & Geographical-temporal & $0.885(0.880-0.890)$ & \\
\hline & Internal-external: Meta-analysis* & Geographical-temporal & $0.889(0.850-0.928)$ & $53.4 \%(24.3 \%-71.3 \%)$ \\
\hline \multirow[t]{7}{*}{ Calibration slope } & Internal: Bootstrap ${ }^{* *}$ & Reproducibility & $1.00718(1.00691-1.00745)$ & \\
\hline & Internal-external: Pooled & Geographical & $0.980(0.958-1.002)$ & \\
\hline & Internal-external: Meta-analysis* & Geographical & $1.033(0.839-1.227)$ & $71.5 \%(56.6 \%-81.2 \%)$ \\
\hline & Internal-external: Pooled & Temporal & $1.010(0.972-1.049)$ & \\
\hline & Internal-external: Meta-analysis & Temporal & Not reported & Not reported \\
\hline & Internal-external: Pooled & Geographical-temporal & $1.002(0.975-1.029)$ & \\
\hline & Internal-external: Meta-analysis* & Geographical-temporal & $1.066(0.813-1.319)$ & $58.2 \%(33.0 \%-73.9 \%)$ \\
\hline \multirow[t]{7}{*}{ Mean calibration } & Internal: Bootstrap** & Reproducibility & $0.00632(0.000582-0.000680)$ & \\
\hline & Internal-external: Pooled & Geographical & $-0.008(-0.039-0.022)$ & \\
\hline & Internal-external: Meta-analysis* & Geographical & $0.065(-0.322-0.452)$ & $84.7 \%(78.3 \%-89.3 \%)$ \\
\hline & Internal-external: Pooled & Temporal & $0.011(-0.042-0.063)$ & \\
\hline & Internal-external: Meta-analysis & Temporal & Not reported & Not reported \\
\hline & Internal-external: Pooled & Geographical-temporal & $-0.006(-0.043-0.031)$ & \\
\hline & Internal-external: Meta-analysis* & Geographical-temporal & $0.039(-0.348-0.427)$ & $65.8 \%(46.4 \%-78.2 \%)$ \\
\hline
\end{tabular}


Figure 1: Joint predictor effects of categorical variables.

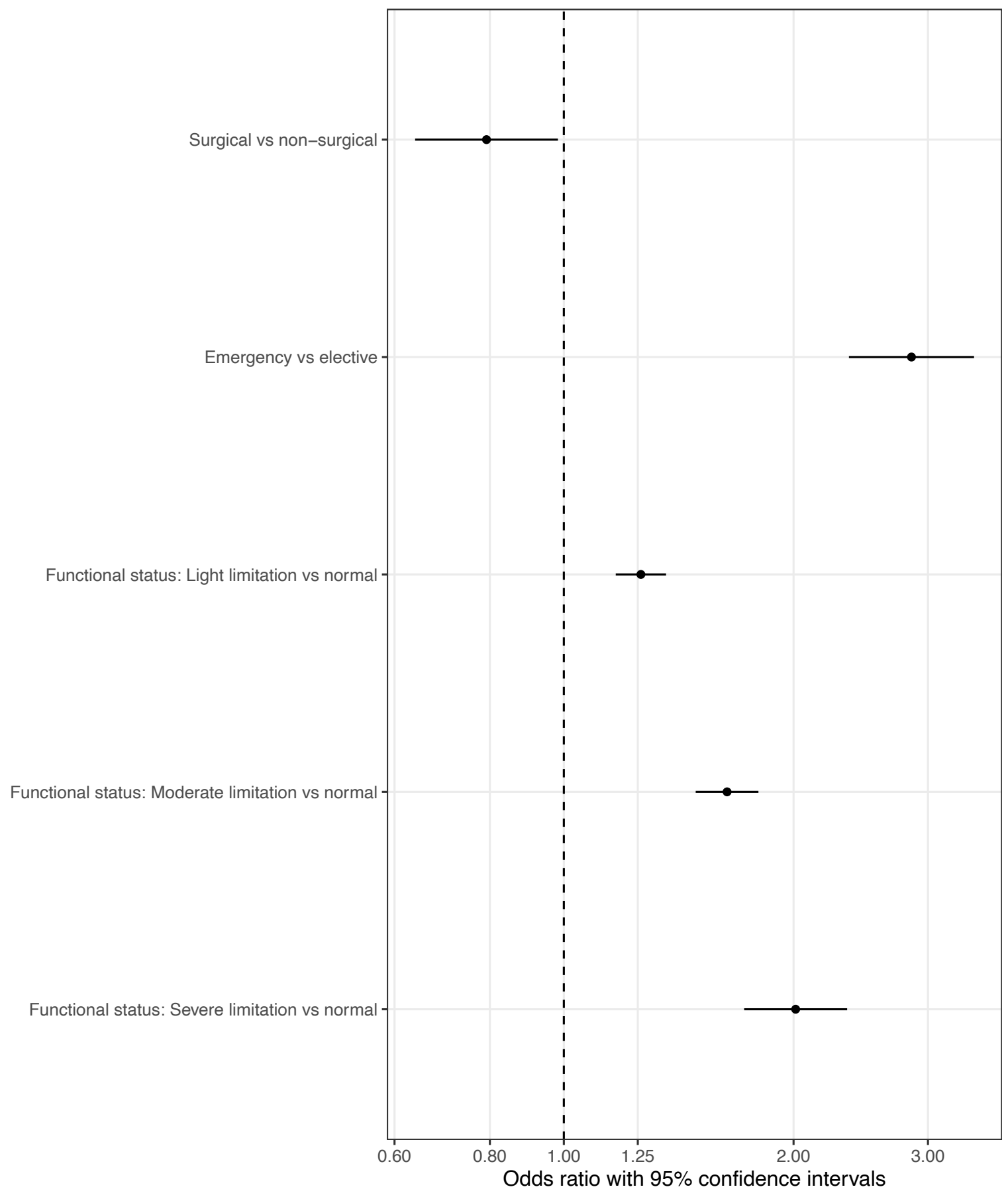


663 Figure 2: Predictor effects of nonlinear modelled interaction effect between age and

664 modified SAPS-II.

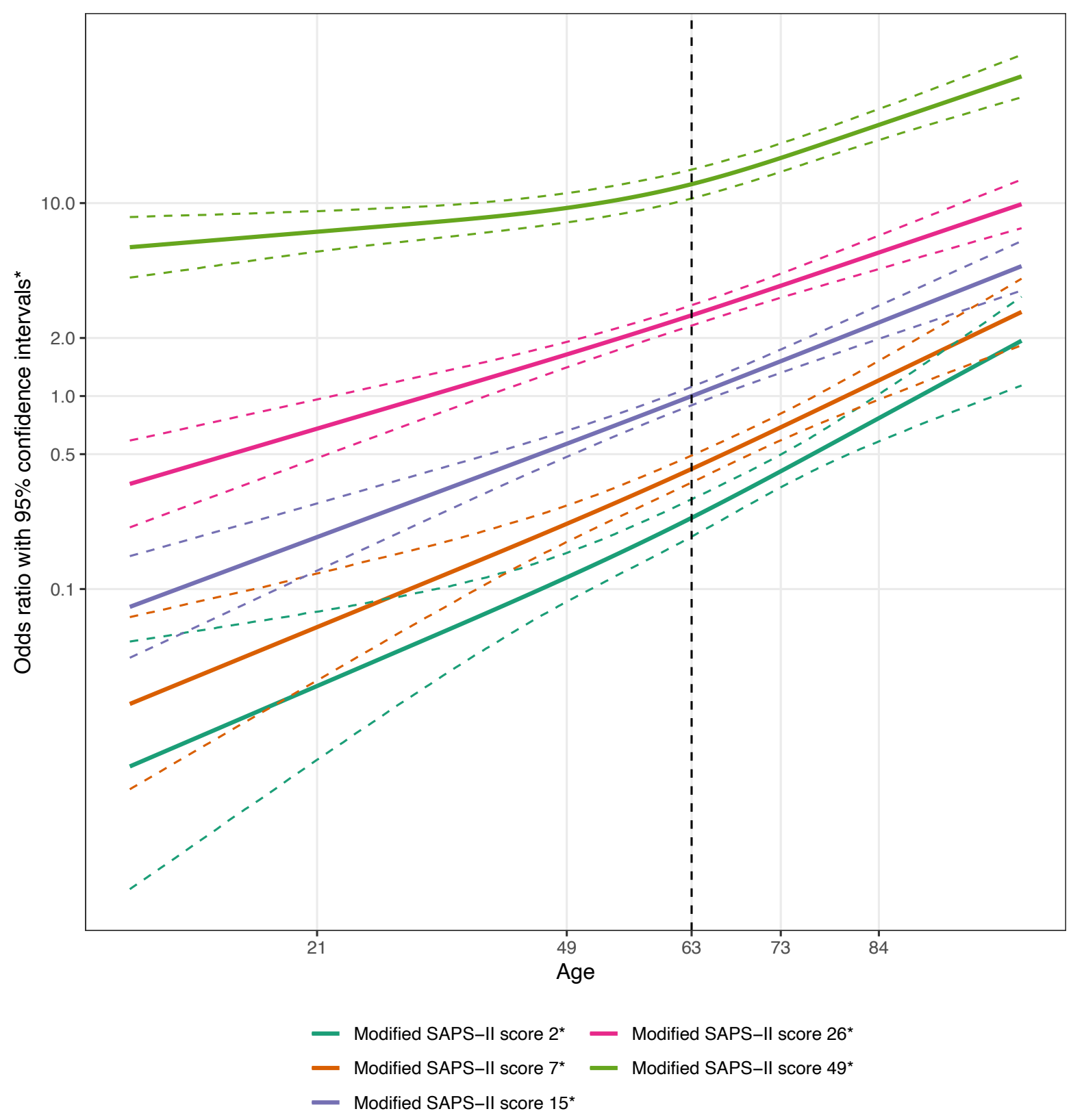

$\mathrm{x}$-axis ticks indicate 5 th, 25th, 50th, 75th and 95th percentiles. ${ }^{*}$ Reference is median age (63 years). ** Estimates adjusted for median modified SAPS-II score (15 points), admission type (non-surgical, elective) 
666 Figure 3: Varying intercept estimates of APACHE-III diagnosis groups from a hierarchical

667 logistic regression model.

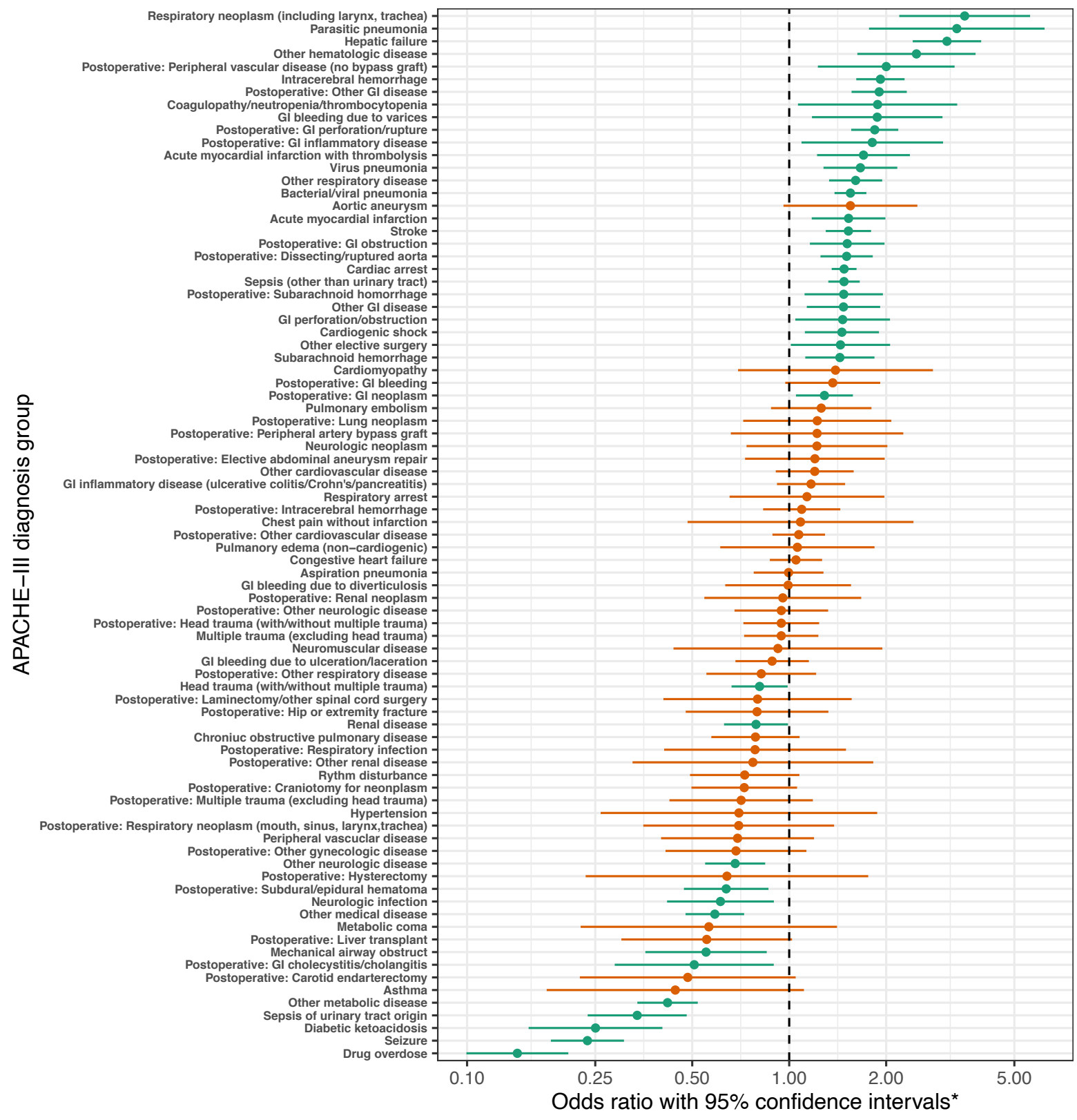

$95 \% \mathrm{Cl}$ excludes odds ratio of $1 \quad 95 \% \mathrm{Cl}$ includes odds ratio of 1

* Exponentiated estimate of varying intercept. 
Figure 4: Discrimination and calibration properties of developed prediction model.

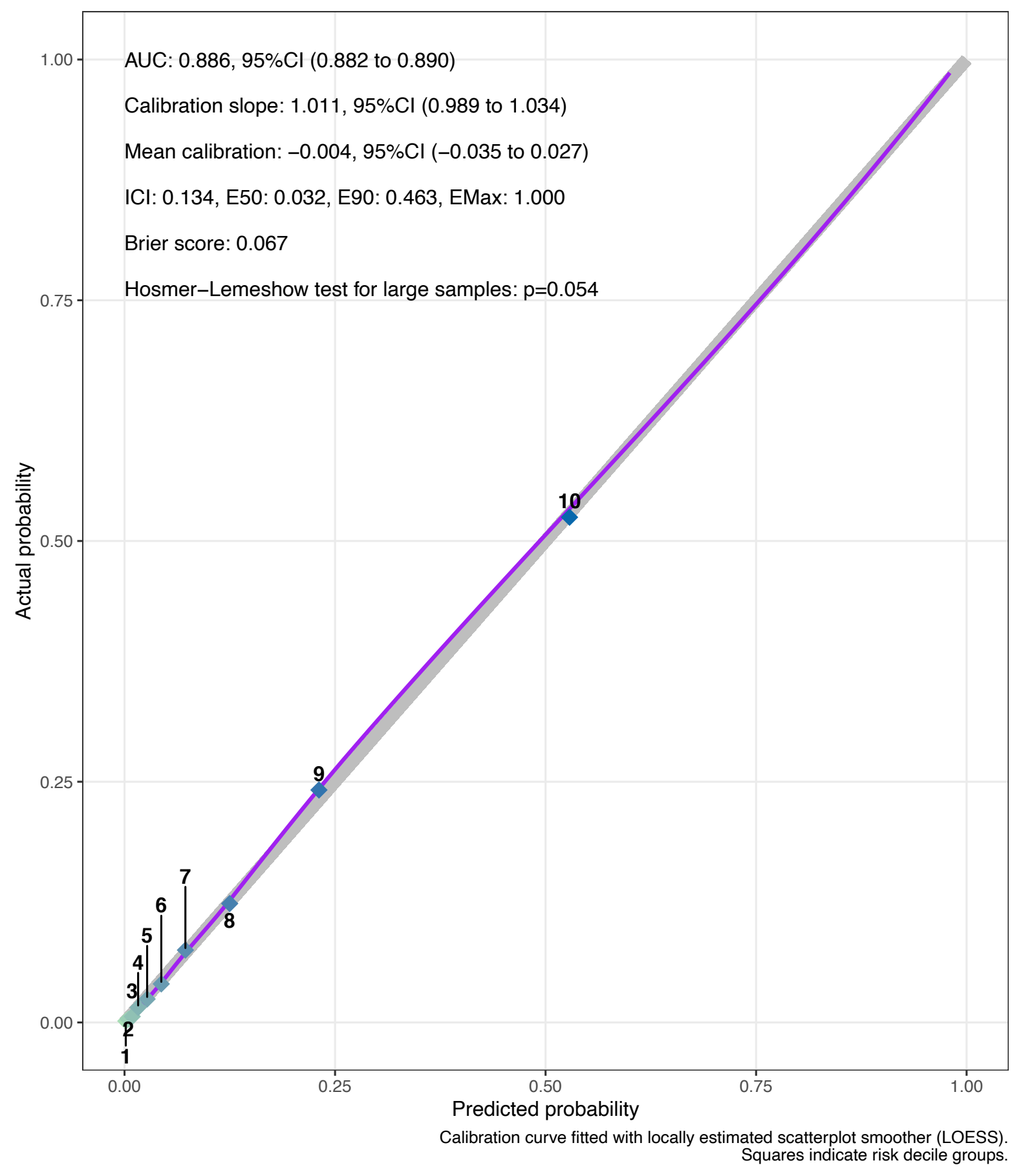




\section{Supplementary material to:}

\section{Mortality prediction in intensive care units including premorbid functional status improved performance and internal validity}

André Moser ${ }^{1, *}$, Matti Reinikainen², Stephan M. Jakob³, Tuomas Selander4, Ville Pettilä5, Olli Kiiski ${ }^{6}$, Tero Varpula7, Rahul Raj ${ }^{8, \dagger}, J^{7}$ kka Takala ${ }^{3, \dagger}$

${ }^{1}$ CTU Bern, University of Bern, Switzerland

2 Department of Anaesthesiology and Intensive Care, Kuopio University Hospital and University of Eastern Finland, Kuopio, Finland

${ }^{3}$ Department of Intensive Care Medicine, Bern University Hospital, University of Bern, Bern, Switzerland ${ }_{4}^{4}$ Science Service Center, Kuopio University Hospital, Kuopio, Finland

${ }^{5}$ University of Helsinki and Helsinki University Hospital, Division of Intensive Care, Helsinki, Finland

${ }^{6}$ Health and Care, Benchmarking services, TietoEvry, Helsinki, Finland

${ }^{7}$ Division of Intensive Care, University of Helsinki and Helsinki University Hospital, Helsinki, Finland

8 Department of Neurosurgery, University of Helsinki and Helsinki University Hospital, Helsinki, Finland

\section{† Senior authors contributed equally.}

* Corresponding author: André Moser, CTU Bern, University of Bern, Mittelstrasse 43, 3012 Bern; e-mail: andre.moser@ctu.unibe.ch 
Supplemental Text 1: Modified SAPS-II score formula.

Modified SAPS-II score $=$ SAPS-II score $-7 *$ I Age $>=40 \&$ Age $<60]-12 *$ I Age $>=60 \&$ Age $<70]-$ 15*I[Age $>=70 \&$ Age $<75]-16 *$ I[Age $>=75 \&$ Age $<80]-18 *$ I $[$ Age $>=80]-6 *$ I[OPERATIVE=0] 8*I[OPERATIVE $=1$ \& EMERGENCY=1],

where $\mathrm{I}[\mathrm{X}]$ is an indicator function, i.e. $\mathrm{I}[\mathrm{X}]=1$ if $\mathrm{X}$ is fulfilled, and 0 otherwise.

Supplemental Text 2: In-hospital mortality prediction formula.

$\operatorname{logit}^{-1}(\mathrm{Y})=-\mathbf{4 . 1 2 3}+0.406 *$ AGE_STD $-0.004 *\left\{\left[\left(\mathrm{AGE} \_S T D-\mathrm{k} 1 \_\mathrm{AGE}\right)^{3}\right]^{+}-[\text {AGE_STD }]^{+}\right.$* $\left(\mathrm{k} 3 \_A G E-\mathrm{k} 1 \text { AGE) /k3_AGE - [(AGE_STD - k3_AGE) }\right]^{+}$* k1_AGE/k3_AGE $\} /\left(\mathrm{k} 3 \_A G E-\right.$ $\left.\mathrm{k} 1 \_A G E\right)^{2}+\mathbf{1 . 2 5 2} *$ SAPSMODIFIED_STD $-\mathbf{0 . 6 7 7} *\{$ [(SAPSMODIFIED_STD k1_SAPSMODIFIED $\left.)^{3}\right]^{+}-\left[\text {SAPSMODIFIED_STD }{ }^{3}\right]^{+}$* $(\mathrm{k} 3$ _SAPSMODIFIED k1_SAPSMODIFIED)/k3_SAPSMODIFIED - [(SAPSMODIFIED_STD - k3_SAPSMODIFIED) $]^{+}$ * (k1_SAPSMODIFIED) / (k3_SAPSMODIFIED) $\} /$ (k3_ SAPSMODIFIED - k1_

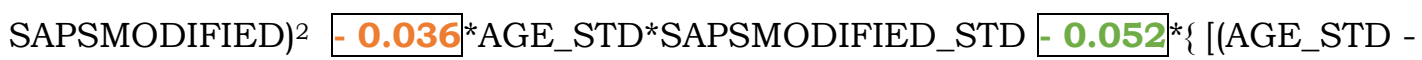
$\left.\left.\left.\mathrm{k} 1 \_\mathrm{AGE}\right)^{3}\right]^{+}-\left[\mathrm{AGE} \_\mathrm{STD}\right]^{+}\right]^{+}$(k3_AGE - k1_AGE)/k3_AGE - [(AGE_STD - k3_AGE $\left.)^{3}\right]^{+}$* k1_AGE/k3_AGE $\} /\left(\mathrm{k} 3 \_A G E-\mathrm{k} 1\right.$ _AGE) ${ }^{2 *}$ SAPSMODIFIED_STD $0.066 * A G E \_S T D *\{$ [(SAPSMODIFIED_STD - k1_SAPSMODIFIED) $\left.]^{3}\right]^{+}$- [SAPSMODIFIED_STD $]^{+}$* (k3_SAPSMODIFIED - k1_SAPSMODIFIED)/k3_SAPSMODIFIED - [(SAPSMODIFIED_STD k3_SAPSMODIFIED) $\left.{ }^{3}\right]^{+}$* (k1_SAPSMODIFIED)/k3_SAPSMODIFIED $\} /(\mathrm{k} 3$ _ SAPSMODIFIED $\mathrm{k} 1 \_$SAPSMODIFIED $)^{2}+\mathbf{0 . 1 0 8} *\left\{\left[\left(\mathrm{AGE} \_\mathrm{STD}-\mathrm{k} 1 \_\mathrm{AGE}\right)^{3}\right]^{+}-\left[\text {AGE_STD }^{3}\right]^{+}\right.$* $\left(\mathrm{k} 3 \_\mathrm{AGE}-\right.$ $\left.\left.\mathrm{k} 1 \_\mathrm{AGE}\right) / \mathrm{k} 3 \_A G E-\left[\left(\mathrm{AGE} \_\mathrm{STD}-\mathrm{k} 3 \_\mathrm{AGE}\right)^{3}\right]^{+*} \mathrm{k} 1 \_\mathrm{AGE} / \mathrm{k} 3 \_\mathrm{AGE}\right\} /\left(\mathrm{k} 3 \_\mathrm{AGE}-\mathrm{k} 1 \_\mathrm{AGE}\right)^{2 *}\{$ [(SAPSMODIFIED_STD - k1_SAPSMODIFIED) $\left.]^{3}\right]^{+}$- [SAPSMODIFIED_STD $\left.{ }^{3}\right]^{+}$* (k3_SAPSMODIFIED - k1_SAPSMODIFIED)/k3_SAPSMODIFIED - [(SAPSMODIFIED_STD k3_SAPSMODIFIED) $\left.{ }^{3}\right]^{+*} \mathrm{k} 1$ _SAPSMODIFIED/k3_SAPSMODIFIED $\} /(\mathrm{k} 3$ _ SAPSMODIFIED $\mathrm{k} 1$ _ SAPSMODIFIED) $)^{2}-0.233 *$ OPERATIVE + 1.049*EMERGENCY $\boxminus$ $0.233 *$ FUNCTIONAL_STATUS $1+0.492 *$ FUNCTIONAL_STATUS $2+0.699 *$ FUNCTIONAL _STATUS3 +

$+\mathbf{0 . 3 7 7} *$ I[APACHE-III DIAGNOSIS CODE=10010] +0.392* ${ }^{\text {[ }}$ [APACHE-III DIAGNOSIS CODE $\left.=10020\right]$ +0.424* ${ }^{*}[$ APACHE-III DIAGNOSIS CODE $=10070]$ $+\mathbf{0 . 5 3 1}{ }^{*}$ [APACHE-III DIAGNOSIS CODE $\left.=10075\right]$ $\mathbf{+ 1 . 1 9 8} *$ [ [APACHE-III DIAGNOSIS CODE $=11010$ ] +1.254* ${ }^{*}$ [APACHE-III DIAGNOSIS CODE $=1$ 1030] +0.438* ${ }^{*}[$ APACHE-III DIAGNOSIS CODE $=11060]$ +0.509*I[APACHE-III DIAGNOSIS CODE $=1$ 1065] -0.594* $[$ [APACHE-III DIAGNOSIS CODE $=11090]$ 
$\mathbf{+ 0 . 4 7 5}{ }^{\star}$ [ [APACHE-III DIAGNOSIS CODE $=1$ 1990] $+\mathbf{1 . 1 2 8}^{*}$ [ [APACHE-III DIAGNOSIS CODE $=12010$ ] $\mathbf{+ 0 . 3 8 2} *$ I [APACHE-III DIAGNOSIS CODE $=12020]$ $\mathbf{+ 0 . 6 2 9} *$ I[APACHE-III DIAGNOSIS CODE $=12030$ ]

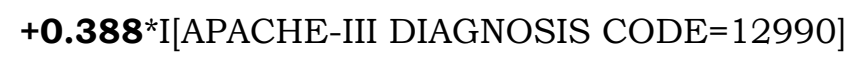
$\mathbf{+ 0 . 6 5 2} *$ I[APACHE-III DIAGNOSIS CODE $=13010$ ] $+\mathbf{0 . 3 6 2} *$ [ [APACHE-III DIAGNOSIS CODE $=13020$ ] $\mathbf{+ 0 . 4 2 3}^{*}$ [ [APACHE-III DIAGNOSIS CODE $=13030$ ] -0.491*I[APACHE-III DIAGNOSIS CODE $=13040$ ] -1.442*I[APACHE-III DIAGNOSIS CODE $=$ 13070] -0.386*I[APACHE-III DIAGNOSIS CODE $=$ 13990] +0.392* ${ }^{\star}$ [APACHE-III DIAGNOSIS CODE $=14010$ ] $\mathbf{- 1 . 0 8 7} *$ I[APACHE-III DIAGNOSIS CODE $=14020$ ] -0.212*I[APACHE-III DIAGNOSIS CODE $=15010$ ] $\mathbf{- 1 . 3 8 5}{ }^{\star}$ [APACHE-III DIAGNOSIS CODE $=16020$ ] -1.943*I[APACHE-III DIAGNOSIS CODE $=16030$ ] $\mathbf{- 0 . 8 6 9} *$ [APACHE-III DIAGNOSIS CODE $=$ 16990] $\mathbf{+ 0 . 6 3 2} *$ [ [APACHE-III DIAGNOSIS CODE $=17010$ ] $+\mathbf{0 . 9 1 0} *$ [ [APACHE-III DIAGNOSIS CODE $=17990$ ] $\mathbf{- 0 . 2 3 7} *$ I APACHE-III DIAGNOSIS CODE $=18010$ ] -0.532*I[APACHE-III DIAGNOSIS CODE $=19010]$ $+\mathbf{0 . 4 1 0} *$ [ [APACHE-III DIAGNOSIS CODE $=20010$ ] $+\mathbf{0 . 6 9 4}{ }^{\star}$ [ [APACHE-III DIAGNOSIS CODE $=20020$ ] $+\mathbf{0 . 6 1} \mathbf{1}^{\star}$ [ [APACHE-III DIAGNOSIS CODE=22010] $\mathbf{+ 0 . 5 9 4} *$ [ [APACHE-III DIAGNOSIS CODE $=22020$ ] $+\mathbf{0 . 4 1 5}{ }^{\star}$ [ [APACHE-III DIAGNOSIS CODE $=22030$ ] $+\mathbf{0 . 2 5 2} *$ [ [APACHE-III DIAGNOSIS CODE $=22060$ ] -0.679*I[APACHE-III DIAGNOSIS CODE $=22070]$ $+\mathbf{0 . 6 4 3}^{*}$ [ [APACHE-III DIAGNOSIS CODE $\left.=22990\right]$ -0.450*I[APACHE-III DIAGNOSIS CODE=23020] +0.390*I[APACHE-III DIAGNOSIS CODE=23030],

where

$\operatorname{logit}^{-1}(\mathrm{x})=\exp (\mathrm{x}) /(1+\exp (\mathrm{x}))$

$[\mathrm{x}]^{+}=0$ if $\mathrm{x}<0$ and $[\mathrm{x}]^{+}=\mathrm{x}$ if $\mathrm{x}>=0$,

$\mathrm{I}[\mathrm{X}]$ is an indicator function, i.e. $\mathrm{I}[\mathrm{X}]=1$ if $\mathrm{X}$ is fulfilled, and 0 otherwise,

SAPSMODIFIED_STD $=($ SAPSMODIFIED-15) $/ 10$,

k1_SAPSMODIFIED=-1.3,

k3_SAPSMODIFIED $=2.6$,

AGE_STD=(AGE-63) /10, 
k1_AGE=-3.3,

k3_AGE $=1.7$.

We note that the central knots k2_SAPSMODIFIED and k2_AGE are both equal to zero due to standardization and are not shown in the formula.

For APACHE-III diagnosis code names see Supplemental Table 1.

Supplemental Text 3: In-hospital mortality prediction formula: Calculation example.

We consider a patient with age 83 , a SAPS-II score of 34 and a severe functional disability (FUNCTIONAL_STATUS3=1). This patient is treated as a non-surgical (OPERATIVE $=0$ ) but emergency (EMERGENCY=1) admission with an APACHE-III diagnosis 'aspiration pneumonia' (APACHE-III DIAGNOSIS CODE=11020).

First, we calculate the modified SAPS-II score (SAPSMODIFIED=10; see $\underline{\text { Supplemental Text }}$ 1). Second, we calculate the values for the standardized age and modified SAPS-II score of AGE_STD $=2.1$ and SAPSMODIFIED_STD $=-0.5$ as described in the formulas above. All calculated numbers can then be put in the formula:

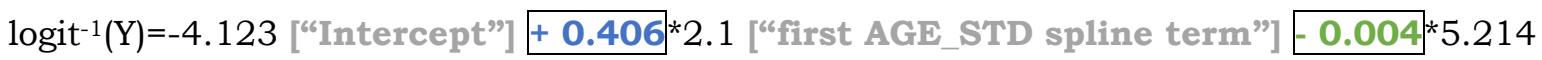
["second AGE_STD spline term"] + 1.252*(-0.5) ["first SAPSMODIFIED_STD spline term"] $-\mathbf{0 . 6 7 7}{ }^{*} 0.0337$ [“second SAPSMODIFIED_STD spline term"] $-0.036 * 2.1^{*}(-0.5)$ ["first interaction spline term"] $-0.052 * 5.214 *(-0.5)$ ["second interaction spline term"] -0.066 * $2.1 * 0.0337$ [“"third interaction spline term"] $+\mathbf{0 . 1 0 8}{ }^{*} 5.214 * 0.0337$ [“fourth interaction spline term"] + 1.049 ["EMERGENCY"] + 0.699 ["FUNCTIONAL_STATUS3"] $=-\mathbf{2 . 0 0 4 4}$

The calculated probability of death is then $\mathrm{P}($ Death $)=\exp (-2.0044) /[1+\exp (-2.0044)]=\mathbf{0 . 1 1 9}$. 
Supplemental Table 1: TRIPOD checklist*

\begin{tabular}{|c|c|c|c|}
\hline Section/Topic & Item & Checklist Item & Section ${ }^{*}$ \\
\hline \multicolumn{4}{|c|}{ Title and abstract } \\
\hline Title & 1 & $\begin{array}{l}\text { Identify the study as developing and/or validating a multivariable prediction } \\
\text { model, the target population, and the outcome to be predicted. }\end{array}$ & Title page \\
\hline Abstract & 2 & $\begin{array}{l}\text { Provide a summary of objectives, study design, setting, participants, sample } \\
\text { size, predictors, outcome, statistical analysis, results, and conclusions. }\end{array}$ & Abstract \\
\hline \multicolumn{4}{|c|}{ 2: } \\
\hline \multirow{2}{*}{$\begin{array}{l}\text { Background } \\
\text { and } \\
\text { objectives }\end{array}$} & $3 a$ & $\begin{array}{l}\text { Explain the medical context (including whether diagnostic or prognostic) and } \\
\text { rationale for developing or validating the multivariable prediction model, } \\
\text { including references to existing models. }\end{array}$ & 1 \\
\hline & $3 b$ & $\begin{array}{l}\text { Specify the objectives, including whether the study describes the development } \\
\text { or validation of the model or both. }\end{array}$ & 1 \\
\hline \multicolumn{4}{|c|}{ S } \\
\hline \multirow{2}{*}{$\begin{array}{l}\text { Source of } \\
\text { data }\end{array}$} & $4 a$ & $\begin{array}{l}\text { Describe the study design or source of data (e.g., randomized trial, cohort, or } \\
\text { registry data), separately for the development and validation data sets, if } \\
\text { applicable. }\end{array}$ & 2.1 \\
\hline & $4 \mathrm{~b}$ & $\begin{array}{l}\text { Specify the key study dates, including start of accrual; end of accrual; and, if } \\
\text { applicable, end of follow-up. }\end{array}$ & 2.2 \\
\hline \multirow{3}{*}{ Participants } & $5 a$ & $\begin{array}{l}\text { Specify key elements of the study setting (e.g., primary care, secondary care, } \\
\text { general population) including number and location of centres. }\end{array}$ & 2.2 \\
\hline & $5 \mathrm{~b}$ & Describe eligibility criteria for participants. & 2.1 \\
\hline & $5 c$ & Give details of treatments received, if relevant. & 2.1 \\
\hline \multirow[t]{2}{*}{ Outcome } & $6 a$ & $\begin{array}{l}\text { Clearly define the outcome that is predicted by the prediction model, including } \\
\text { how and when assessed. }\end{array}$ & 2.4 \\
\hline & $6 b$ & Report any actions to blind assessment of the outcome to be predicted. & - \\
\hline \multirow{2}{*}{ Predictors } & $7 \mathrm{a}$ & $\begin{array}{l}\text { Clearly define all predictors used in developing or validating the multivariable } \\
\text { prediction model, including how and when they were measured. }\end{array}$ & 2.5 \\
\hline & $7 \mathrm{~b}$ & $\begin{array}{l}\text { Report any actions to blind assessment of predictors for the outcome and } \\
\text { other predictors. }\end{array}$ & - \\
\hline Sample size & 8 & Explain how the study size was arrived at. & 2.2 \\
\hline Missing data & 9 & $\begin{array}{l}\text { Describe how missing data were handled (e.g., complete-case analysis, single } \\
\text { imputation, multiple imputation) with details of any imputation method. }\end{array}$ & 2.6 \\
\hline \multirow{5}{*}{$\begin{array}{l}\text { Statistical } \\
\text { analysis } \\
\text { methods }\end{array}$} & $10 \mathrm{a}$ & Describe how predictors were handled in the analyses. & 2.6 \\
\hline & $10 \mathrm{~b}$ & $\begin{array}{l}\text { Specify type of model, all model-building procedures (including any predictor } \\
\text { selection), and method for internal validation. }\end{array}$ & 2.6 \\
\hline & $10 \mathrm{c}$ & For validation, describe how the predictions were calculated. & 2.6 \\
\hline & $10 \mathrm{~d}$ & $\begin{array}{l}\text { Specify all measures used to assess model performance and, if relevant, to } \\
\text { compare multiple models. }\end{array}$ & 2.6 \\
\hline & $10 \mathrm{e}$ & $\begin{array}{l}\text { Describe any model updating (e.g., recalibration) arising from the validation, if } \\
\text { done. }\end{array}$ & - \\
\hline Risk groups & 11 & Provide details on how risk groups were created, if done. & - \\
\hline $\begin{array}{l}\text { Development } \\
\text { vs. validation }\end{array}$ & 12 & $\begin{array}{l}\text { For validation, identify any differences from the development data in setting, } \\
\text { eligibility criteria, outcome, and predictors. }\end{array}$ & 2.6 \\
\hline \multicolumn{4}{|c|}{$0=0,0$} \\
\hline \multirow{3}{*}{ Participants } & $13 a$ & $\begin{array}{l}\text { Describe the flow of participants through the study, including the number of } \\
\text { participants with and without the outcome and, if applicable, a summary of } \\
\text { the follow-up time. A diagram may be helpful. }\end{array}$ & 3.1 \\
\hline & $13 b$ & $\begin{array}{l}\text { Describe the characteristics of the participants (basic demographics, clinical } \\
\text { features, available predictors), including the number of participants with } \\
\text { missing data for predictors and outcome. }\end{array}$ & 3.1 \\
\hline & $13 c$ & $\begin{array}{l}\text { For validation, show a comparison with the development data of the } \\
\text { distribution of important variables (demographics, predictors and outcome). }\end{array}$ & 3.4 \\
\hline \multirow{2}{*}{$\begin{array}{l}\text { Model } \\
\text { development }\end{array}$} & $14 \mathrm{a}$ & Specify the number of participants and outcome events in each analysis. & Suppl Table 3 \\
\hline & $14 \mathrm{~b}$ & $\begin{array}{l}\text { If done, report the unadjusted association between each candidate predictor } \\
\text { and outcome. }\end{array}$ & 3.1 \\
\hline \multirow[t]{2}{*}{$\begin{array}{l}\text { Model } \\
\text { specification }\end{array}$} & $15 a$ & $\begin{array}{l}\text { Present the full prediction model to allow predictions for individuals (i.e., all } \\
\text { regression coefficients, and model intercept or baseline survival at a given time } \\
\text { point). }\end{array}$ & Suppl Text 2 \\
\hline & $15 \mathrm{~b}$ & Explain how to the use the prediction model. & Suppl Text 3 \\
\hline $\begin{array}{l}\text { Model } \\
\text { performance }\end{array}$ & 16 & Report performance measures (with CIs) for the prediction model. & $3.3 ; 3.4$ \\
\hline $\begin{array}{l}\text { Model- } \\
\text { updating }\end{array}$ & 17 & $\begin{array}{l}\text { If done, report the results from any model updating (i.e., model specification, } \\
\text { model performance). }\end{array}$ & 3.4 \\
\hline \multicolumn{4}{|l|}{ Discussion } \\
\hline Limitations & 18 & $\begin{array}{l}\text { Discuss any limitations of the study (such as nonrepresentative sample, few } \\
\text { events per predictor, missing data). }\end{array}$ & 4 \\
\hline Interpretation & $19 \mathrm{a}$ & $\begin{array}{l}\text { For validation, discuss the results with reference to performance in the } \\
\text { development data, and any other validation data. }\end{array}$ & 4 \\
\hline
\end{tabular}




\begin{tabular}{|c|r|l|c|}
\hline & $19 \mathrm{~b}$ & $\begin{array}{l}\text { Give an overall interpretation of the results, considering objectives, limitations, } \\
\text { results from similar studies, and other relevant evidence. }\end{array}$ & $\mathbf{4}$ \\
\hline Implications & 20 & $\begin{array}{l}\text { Discuss the potential clinical use of the model and implications for future } \\
\text { research. }\end{array}$ & $\mathbf{4}$ \\
\hline Other information & \multicolumn{3}{|l|}{$\begin{array}{c}\text { Suppl } \\
\text { Material; } \\
\text { Availability of } \\
\text { data statment }\end{array}$} \\
\hline $\begin{array}{l}\text { Supplementar } \\
\text { information }\end{array}$ & 21 & $\begin{array}{l}\text { Provide information about the availability of supplementary resources, such as } \\
\text { study protocol, Web calculator, and data sets. }\end{array}$ & Funding \\
\hline Funding & 22 & Give the source of funding and the role of the funders for the present study. &
\end{tabular}

Source: www.tripod-statement.org

* The last column has been changed from the original TRIPOD checklist from "Page" to "Section". 
Supplemental Table 2: APACHE-III diagnosis coding (Source: Knaus et al. [20]).

\begin{tabular}{|c|c|}
\hline APACHE-III diagnosis & Name \\
\hline 10010 & Cardiogenic shock \\
\hline 10020 & Cardiac arrest \\
\hline 10030 & Aortic aneurysm \\
\hline 10040 & Congestive heart failure \\
\hline 10045 & Cardiomyopathy \\
\hline 10050 & Peripheral vascular disease \\
\hline 10060 & Rhythm disturbance \\
\hline 10065 & Chest pain without infarction \\
\hline 10070 & Acute myocardial infarction \\
\hline 10075 & Acute myocardial infarction with thrombolysis \\
\hline 10080 & Hypertension \\
\hline 10990 & Other cardiovascular disease \\
\hline 11010 & Parasitic pneumonia \\
\hline 11020 & Aspiration pneumonia \\
\hline 11030 & Respiratory neoplasm (including larynx, trachea) \\
\hline 11040 & Respiratory arrest \\
\hline 11050 & Pulmonary edema (non-cardiogenic) \\
\hline 11060 & Bacterial/viral pneumonia \\
\hline 11065 & Virus pneumonia \\
\hline 11070 & Chronic obstructive pulmonary disease \\
\hline 11080 & Pulmonary embolism \\
\hline 11090 & Mechanical airways obstruct \\
\hline 11100 & Asthma \\
\hline 11990 & Other respiratory disease \\
\hline 12010 & Hepatic failure \\
\hline 12020 & GI perforation/obstruction \\
\hline 12030 & GI bleeding due to varices \\
\hline 12040 & GI inflammatory disease (ulcerative colitis/Crohn's/pancreatitis) \\
\hline 12050 & GI bleeding due to ulceration/laceration \\
\hline 12060 & GI bleeding due to diverticulosis \\
\hline 12990 & Other GI disease \\
\hline 13010 & Intracerebral hemorrhage \\
\hline 13020 & Subarachnoid hemorrhage \\
\hline 13030 & Stroke \\
\hline 13040 & Neurologic infection \\
\hline 13050 & Neurologic neoplasm \\
\hline 13060 & Neuromuscular disease \\
\hline 13070 & Seizure \\
\hline 13990 & Other neurologic disease \\
\hline 14010 & Sepsis (other than urinary tract) \\
\hline
\end{tabular}




\begin{tabular}{|c|c|}
\hline 14020 & Sepsis of urinary tract origin \\
\hline 15010 & Head trauma (with/without multiple trauma) \\
\hline 15020 & Multiple trauma (excluding head trauma) \\
\hline 16010 & Metabolic coma \\
\hline 16020 & Diabetic ketoacidosis \\
\hline 16030 & Drug overdose \\
\hline 16990 & Other metabolic disease \\
\hline 17010 & Coagulopathy/neutropenia/thrombocytopenia \\
\hline 17990 & Other hematologic disease \\
\hline 18010 & Renal disease \\
\hline 19010 & Other medical disease \\
\hline 20010 & Postoperative: Dissecting/ruptured aorta \\
\hline 20020 & Postoperative: Peripheral vascular disease (no bypass graft) \\
\hline 20040 & Postoperative: Elective abdominal aneurysm repair \\
\hline 20050 & Postoperative: Peripheral artery bypass graft \\
\hline 20060 & Postoperative: Carotid endarterectomy \\
\hline 20990 & Postoperative: Other cardiovascular disease \\
\hline 21010 & Postoperative: Respiratory infection \\
\hline 21020 & Postoperative: Lung neoplasm \\
\hline 21030 & Postoperative: Respiratory neoplasm (mouth, sinus, larynx, trachea) \\
\hline 21990 & Postoperative: Other respiratory disease \\
\hline 22010 & Postoperative: GI perforation/rupture \\
\hline 22020 & Postoperative: GI inflammatory disease \\
\hline 22030 & Postoperative: GI obstruction \\
\hline 22040 & Postoperative: GI bleeding \\
\hline 22050 & Postoperative: Liver transplant \\
\hline 22060 & Postoperative: GI neoplasm \\
\hline 22070 & Postoperative: GI cholecystitis/cholangitis \\
\hline 22990 & Postoperative: Other GI disease \\
\hline 23010 & Postoperative: Intracerebral hemorrhage \\
\hline 23020 & Postoperative: Subdural/epidural hematoma \\
\hline 23030 & Postoperative: Subarachnoid hemorrhage \\
\hline 23040 & Postoperative: Laminectomy/other spinal cord surgery \\
\hline 23050 & Postoperative: Craniotomy for neoplasm \\
\hline 23990 & Postoperative: Other neurologic disease \\
\hline 24010 & Postoperative: Head trauma (with/without multiple trauma) \\
\hline 24020 & Postoperative: Multiple trauma (excluding head trauma) \\
\hline 25010 & Postoperative: Renal neoplasm \\
\hline 25990 & Postoperative: Other renal disease \\
\hline 26010 & Postoperative: Hysterectomy \\
\hline 26990 & Postoperative: Other gynecologic disease \\
\hline 27010 & Postoperative: Hip or extremity fracture \\
\hline 0 & Postoperative: Other elective surgery \\
\hline
\end{tabular}


Supplemental Table 3: Number of admissions and number of deaths, by unit and year.

\begin{tabular}{|c|c|c|c|}
\hline Unit & Year & Number of admissions & Number of deaths \\
\hline A & 2015 & 584 & 91 \\
\hline A & 2016 & 685 & 87 \\
\hline A & 2017 & 588 & 79 \\
\hline B & 2015 & 336 & 34 \\
\hline B & 2016 & 395 & 57 \\
\hline B & 2017 & 397 & 50 \\
\hline $\mathrm{C}$ & 2015 & 463 & 67 \\
\hline $\mathrm{C}$ & 2016 & 474 & 80 \\
\hline $\mathrm{C}$ & 2017 & 504 & 59 \\
\hline $\mathrm{D}$ & 2015 & 432 & 49 \\
\hline $\mathrm{D}$ & 2016 & 450 & 46 \\
\hline $\mathrm{D}$ & 2017 & 405 & 63 \\
\hline $\mathrm{E}$ & 2015 & 350 & 61 \\
\hline $\mathrm{E}$ & 2016 & 350 & 51 \\
\hline $\mathrm{E}$ & 2017 & 302 & 43 \\
\hline $\mathrm{F}$ & 2015 & 342 & 46 \\
\hline $\mathrm{F}$ & 2016 & 346 & 44 \\
\hline $\mathrm{F}$ & 2017 & 386 & 53 \\
\hline G & 2015 & 319 & 41 \\
\hline $\mathrm{G}$ & 2016 & 290 & 52 \\
\hline $\mathrm{G}$ & 2017 & 318 & 52 \\
\hline $\mathrm{H}$ & 2015 & 260 & 51 \\
\hline $\mathrm{H}$ & 2016 & 285 & 58 \\
\hline $\mathrm{H}$ & 2017 & 273 & 53 \\
\hline I & 2015 & 284 & 50 \\
\hline I & 2016 & 271 & 43 \\
\hline I & 2017 & 347 & 49 \\
\hline $\mathrm{J}$ & 2015 & 442 & 79 \\
\hline $\mathrm{J}$ & 2016 & 471 & 72 \\
\hline $\mathrm{J}$ & 2017 & 373 & 55 \\
\hline K & 2015 & 233 & 39 \\
\hline $\mathrm{K}$ & 2016 & 230 & 18 \\
\hline $\mathrm{K}$ & 2017 & 230 & 40 \\
\hline $\mathrm{L}$ & 2015 & 267 & 38 \\
\hline $\mathrm{L}$ & 2016 & 318 & 38 \\
\hline $\mathrm{L}$ & 2017 & 335 & 48 \\
\hline $\mathrm{M}$ & 2015 & 1255 & 134 \\
\hline $\mathrm{M}$ & 2016 & 1286 & 132 \\
\hline M & 2017 & 1332 & 121 \\
\hline $\mathrm{N}$ & 2015 & 87 & 10 \\
\hline
\end{tabular}




\begin{tabular}{|c|c|c|c|}
\hline $\mathrm{N}$ & 2016 & 151 & 11 \\
\hline $\mathrm{N}$ & 2017 & 131 & 15 \\
\hline $\mathrm{O}$ & 2015 & 428 & 39 \\
\hline $\mathrm{O}$ & 2016 & 337 & 46 \\
\hline $\mathrm{O}$ & 2017 & 371 & 44 \\
\hline $\mathrm{P}$ & 2017 & 380 & 18 \\
\hline $\mathrm{Q}$ & 2015 & 964 & 85 \\
\hline $\mathrm{Q}$ & 2016 & 970 & 59 \\
\hline $\mathrm{Q}$ & 2017 & 952 & 82 \\
\hline $\mathrm{R}$ & 2015 & 5218 & 461 \\
\hline $\mathrm{R}$ & 2016 & 5190 & 467 \\
\hline $\mathrm{R}$ & 2017 & 5120 & 489 \\
\hline $\mathrm{S}$ & 2015 & 1866 & 145 \\
\hline $\mathrm{S}$ & 2016 & 1844 & 159 \\
\hline $\mathrm{S}$ & 2017 & 1690 & 140 \\
\hline $\mathrm{T}$ & 2015 & 1588 & 140 \\
\hline $\mathrm{T}$ & 2016 & 1742 & 143 \\
\hline $\mathrm{T}$ & 2017 & 1769 & 136 \\
\hline $\mathrm{U}$ & 2015 & 1585 & 136 \\
\hline $\mathrm{U}$ & 2016 & 1573 & 141 \\
\hline $\mathrm{U}$ & 2017 & 1700 & 153 \\
\hline $\mathrm{V}$ & 2015 & 1099 & 128 \\
\hline $\mathrm{V}$ & 2016 & 1473 & 167 \\
\hline $\mathrm{V}$ & 2017 & 1704 & 192 \\
\hline W & 2015 & 1326 & 167 \\
\hline W & 2016 & 1344 & 185 \\
\hline W & 2017 & 1400 & 179 \\
\hline$Z$ & 2015 & 14 & 3 \\
\hline
\end{tabular}


Supplemental Figure 1: Crude and adjusted predictor effects of categorical variables.

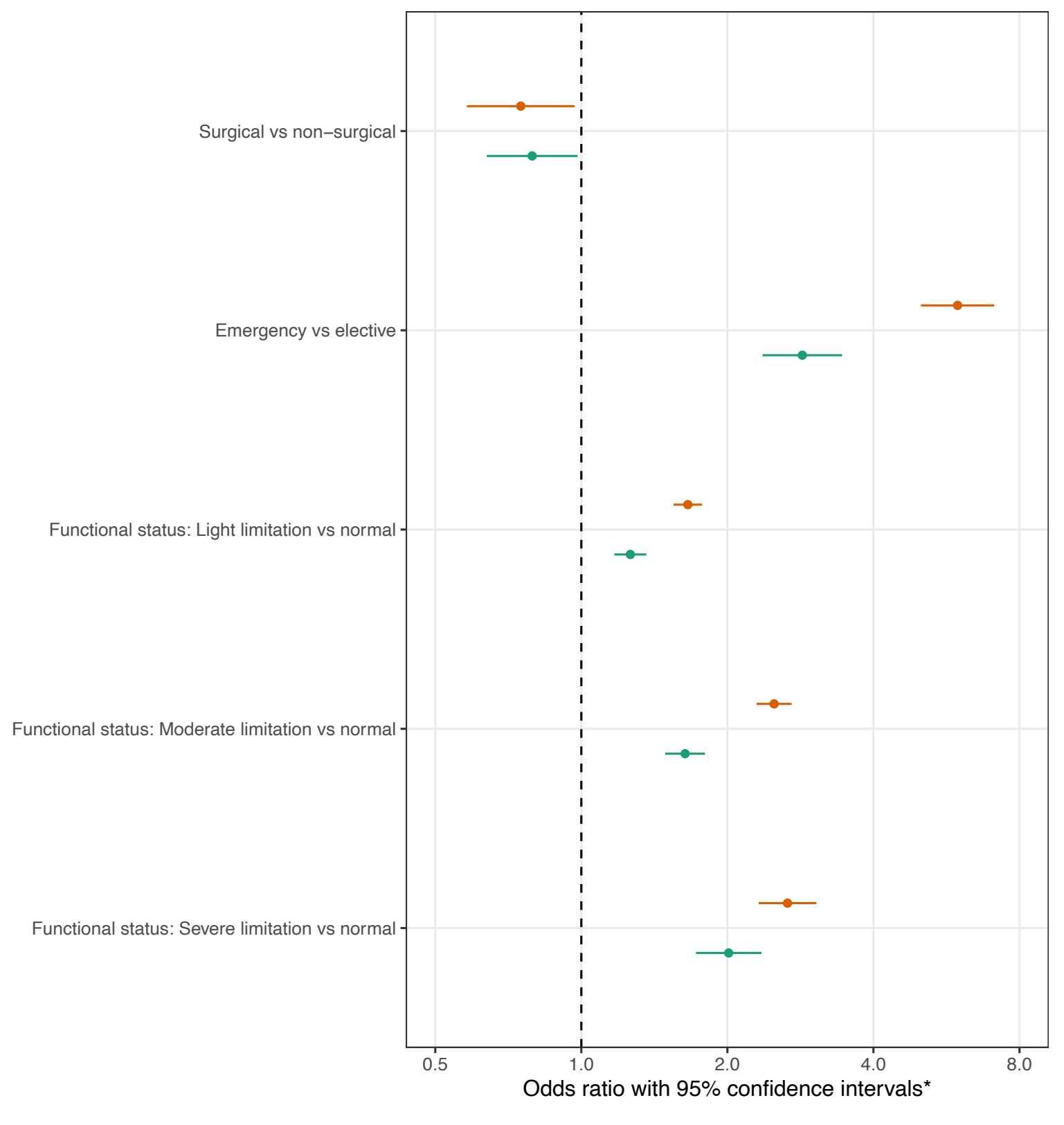

$\oint$ Adjusted $^{\star *} \nmid$ Crude $^{* * *}$

* Estimates from hierarchical model with APACHE-III diagnosis as grouping variable. ${ }^{* \star}$ Adjusted for all listed variables, age and modified SAPS-II score. ${ }_{* \star \star}$ Uses one single variable of the listed variables. 
Supplemental Figure 2: Crude and adjusted predictor effects of nonlinear modelled age and modified SAPS-II score.

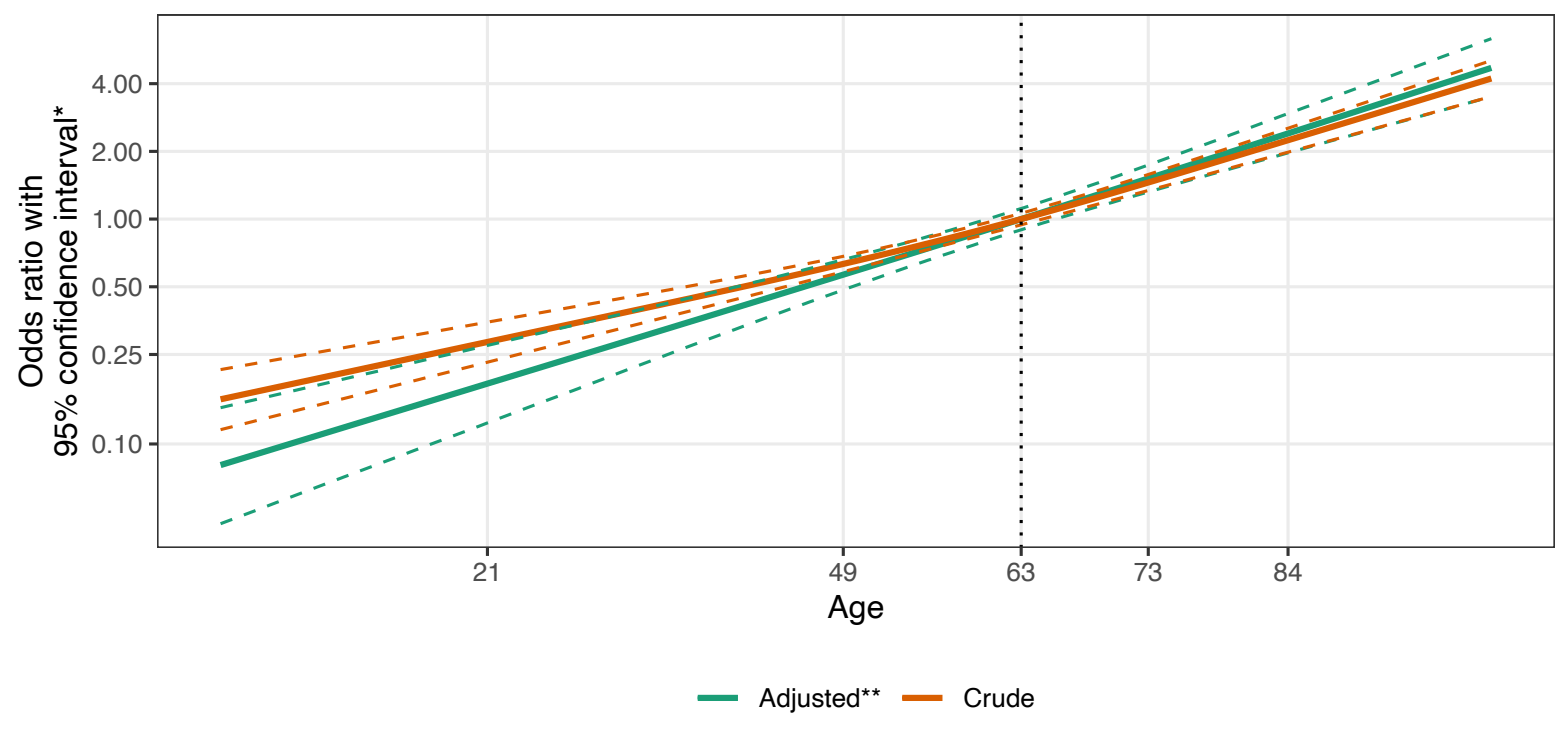

$\mathrm{x}$-axis ticks indicate 5 th, 25th, 50th, 75th and 95th percentiles. * Estimates from a hierarchical model with APACHE-III diagnosis as grouping variable. Reference is a median age (63 years) for crude and adjusted models. ** Estimates adjusted for median modified SAPS-II score (15 points), admission type (non-surgical, elective)

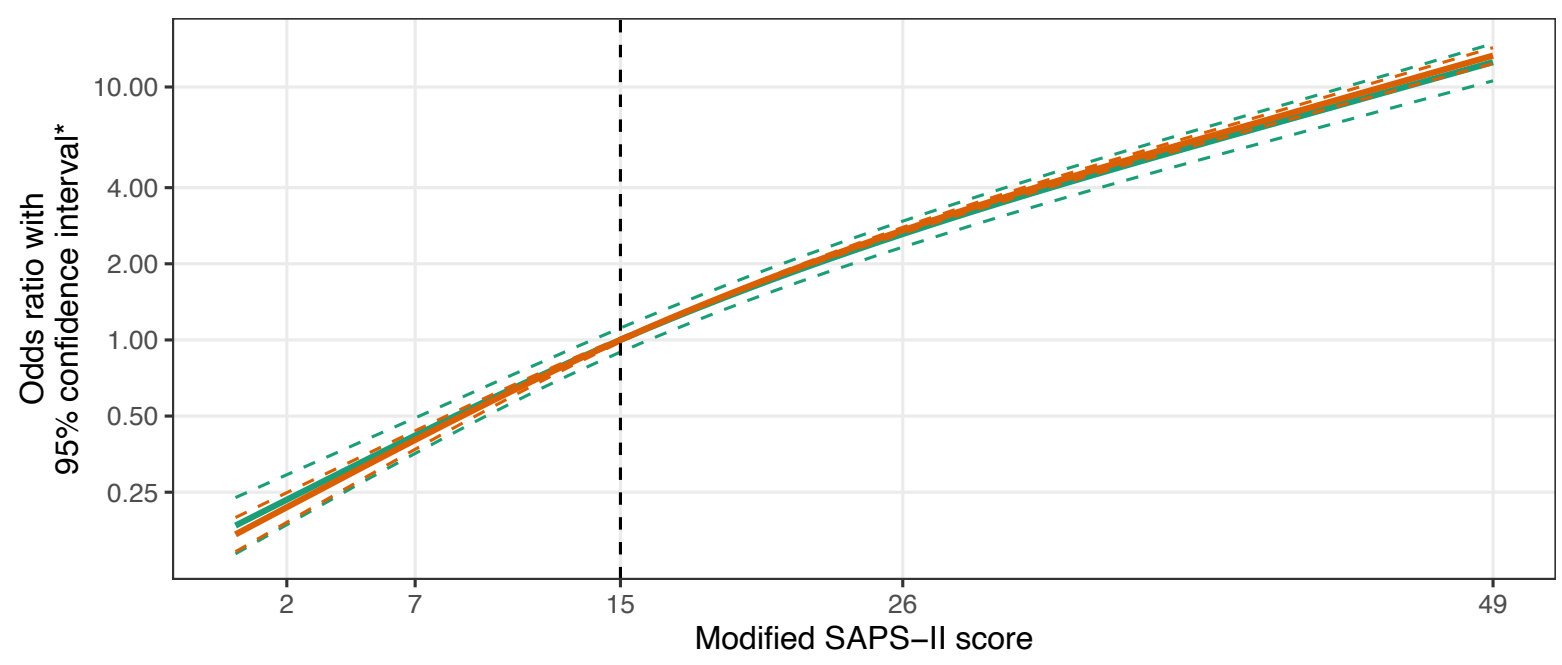

- Adjusted** Crude

$\mathrm{x}$-axis ticks indicate 5th, 25th, 50th, 75th and 95th percentiles. * Estimates from a hierarchical model with APACHE-III diagnosis as grouping variable. Reference is a median modified SAPS-II score (15 points) for crude and adjusted models. ** Estimates adjusted for median age (63 years), admission type (non-surgical, elective) and normal functional status. 
Supplemental Figure 3: Discrimination and calibration performance of mortality predictions from the original SAPS-II score.

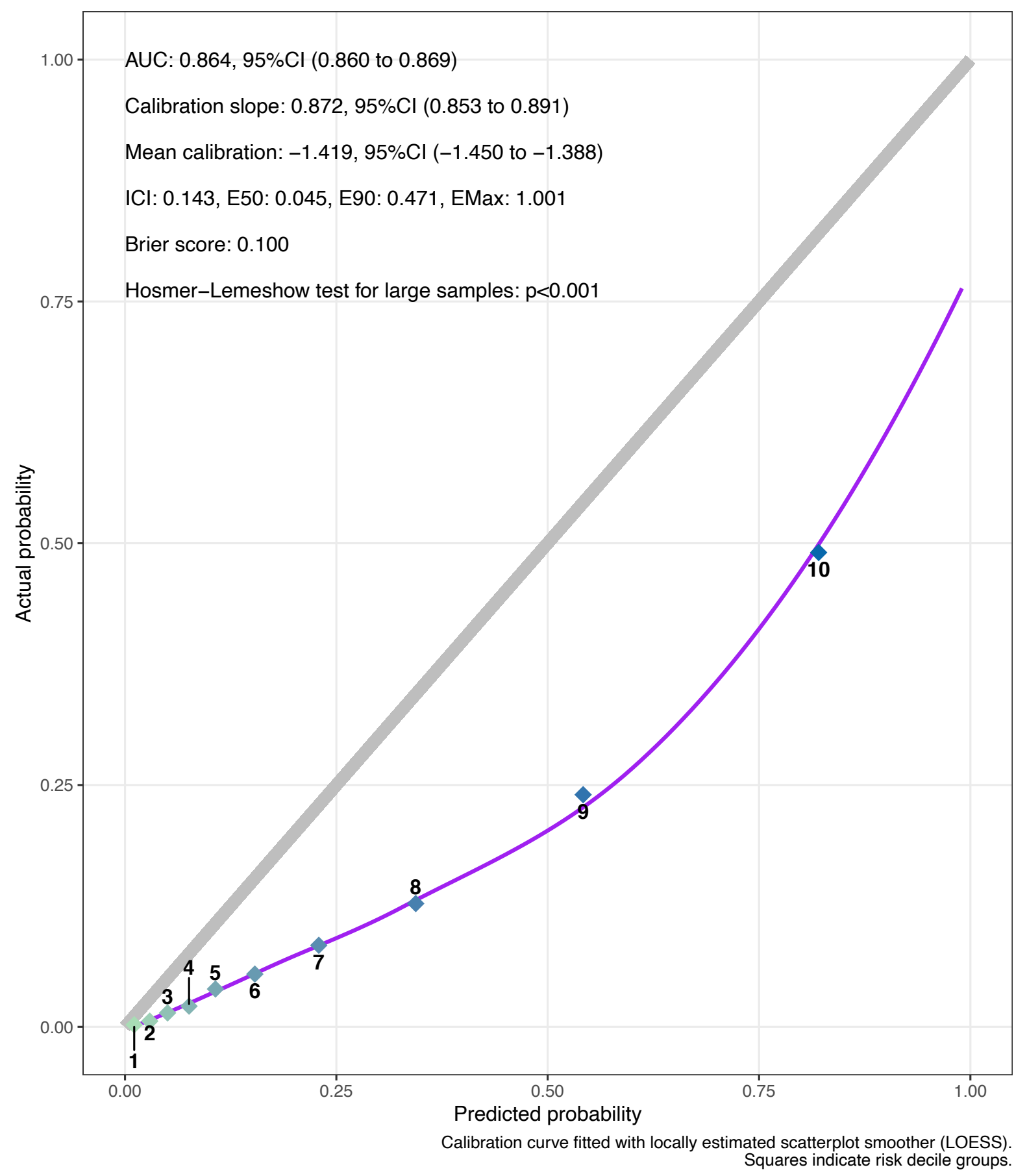


Supplemental Figure 4: Receiver operating characteristics curves for mortality predictions from developed prediction models, the sensitivity prediction model and the original SAPS-II score.

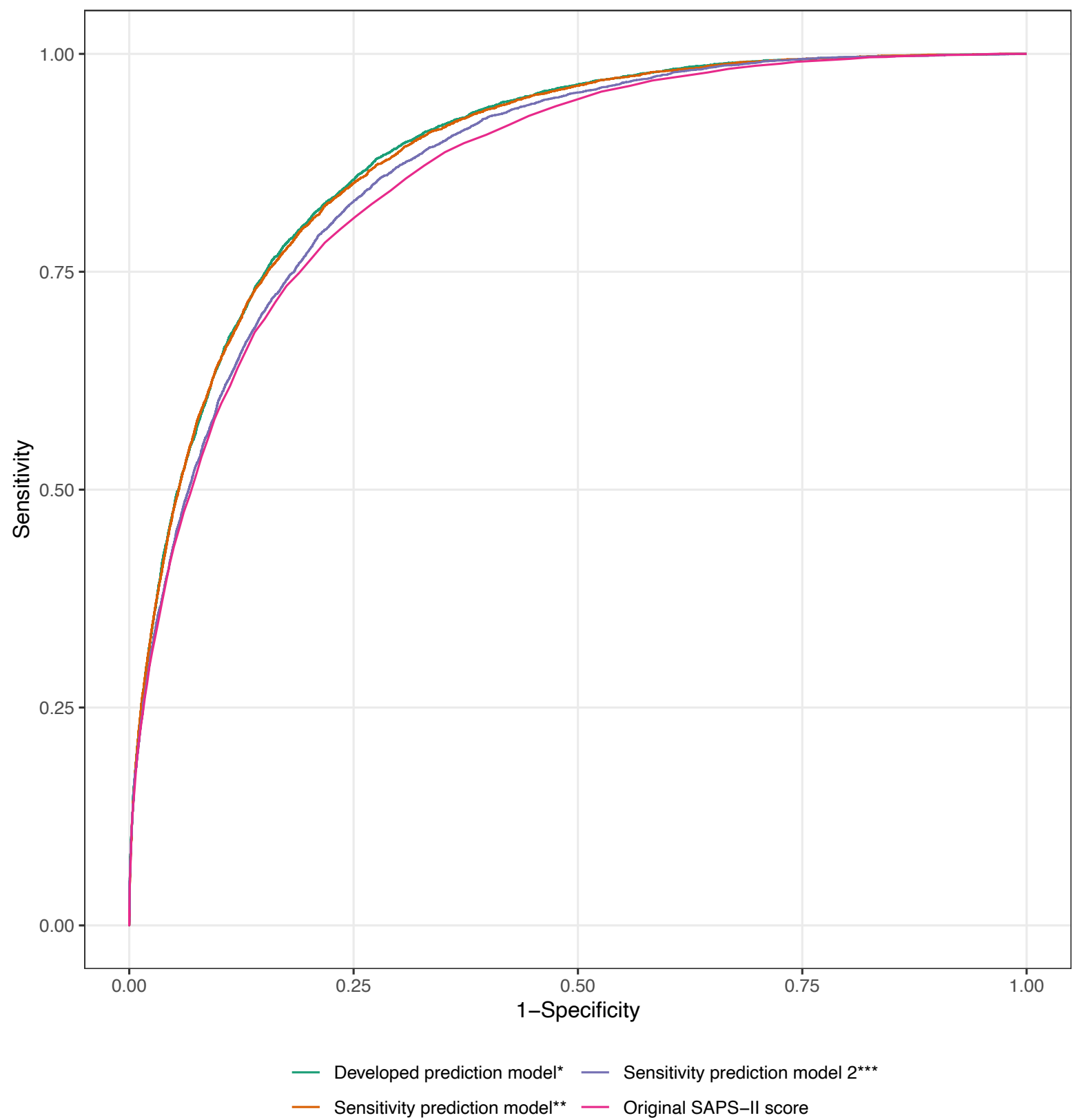

* From an hierarchical logistic regression model with predictors age, a modified SAPS-II score, admission type, functional status, and accounting for APACHE-III diagnosis groups. ** Excluding predictor premorbid functional status from the developed prediction model. *** From an ordinary logistic regression model with same predictors as the developed prediction model, but not accounting for APACHE-III diagnosis groups. 
Supplemental Figure 5: AUC estimates from membership models from leave-one-hospitalout validation samples.

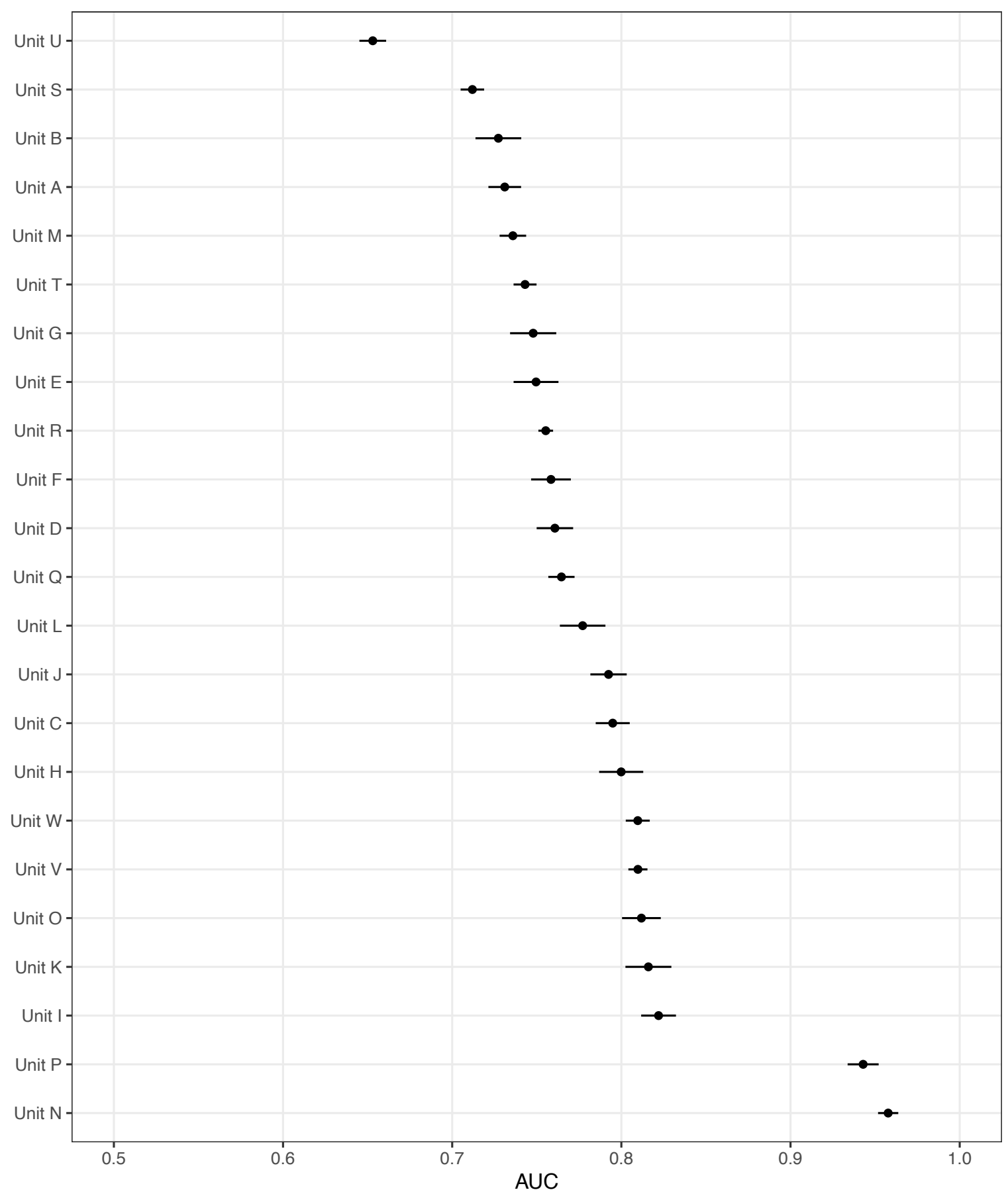


Supplemental Figure 6: Standardized standard deviations for assessing the relatedness of the leave-one-hospital-out validation samples and the development sample.

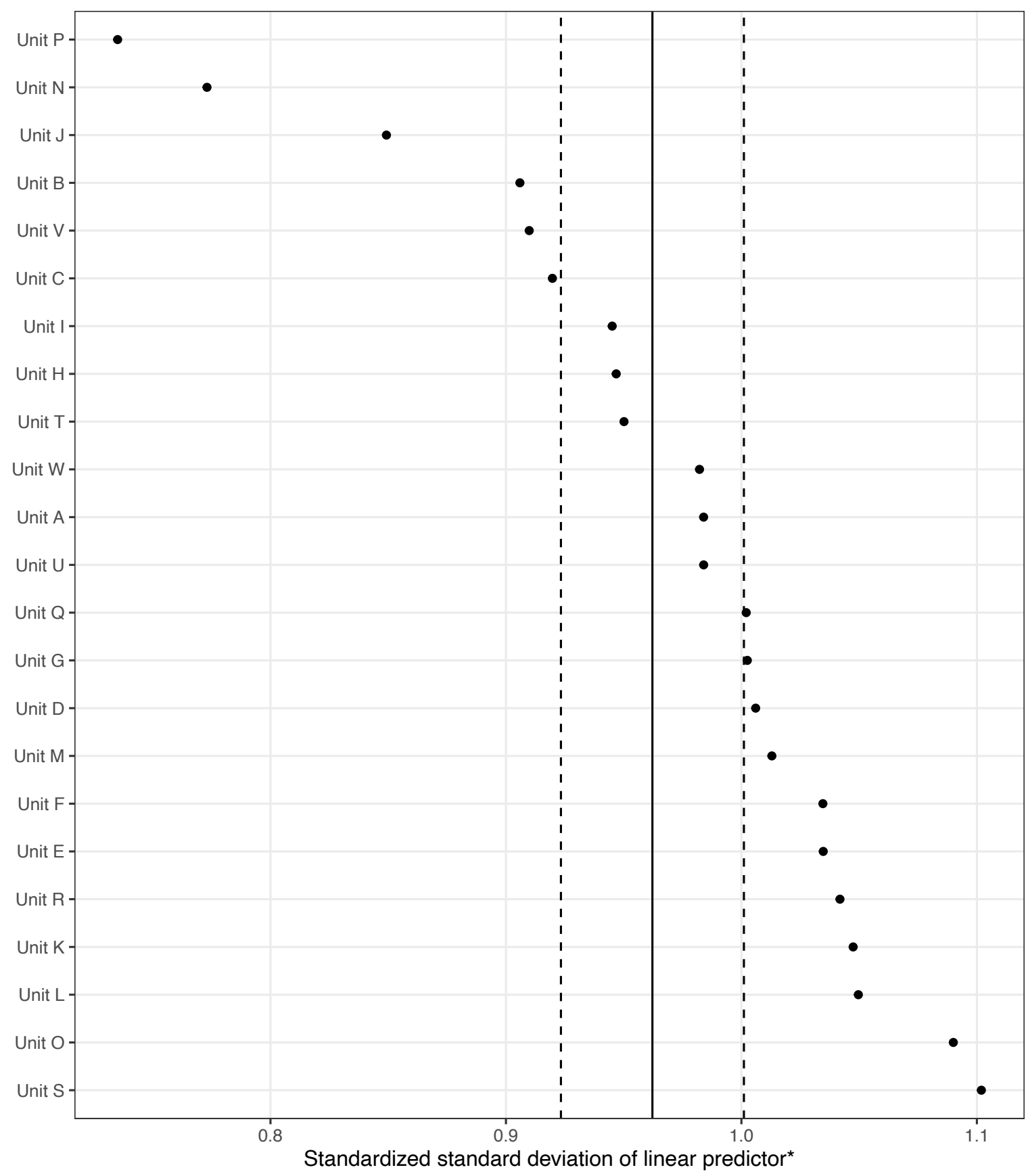

* Standard deviation of validation sample divided by standard deviation of development sample. Mean value of all units indicated by vertical lines: $0.962,95 \% \mathrm{Cl}(0.923,1.001)$ 
Supplemental Figure 7: Geographic transportability: Pooled estimates.

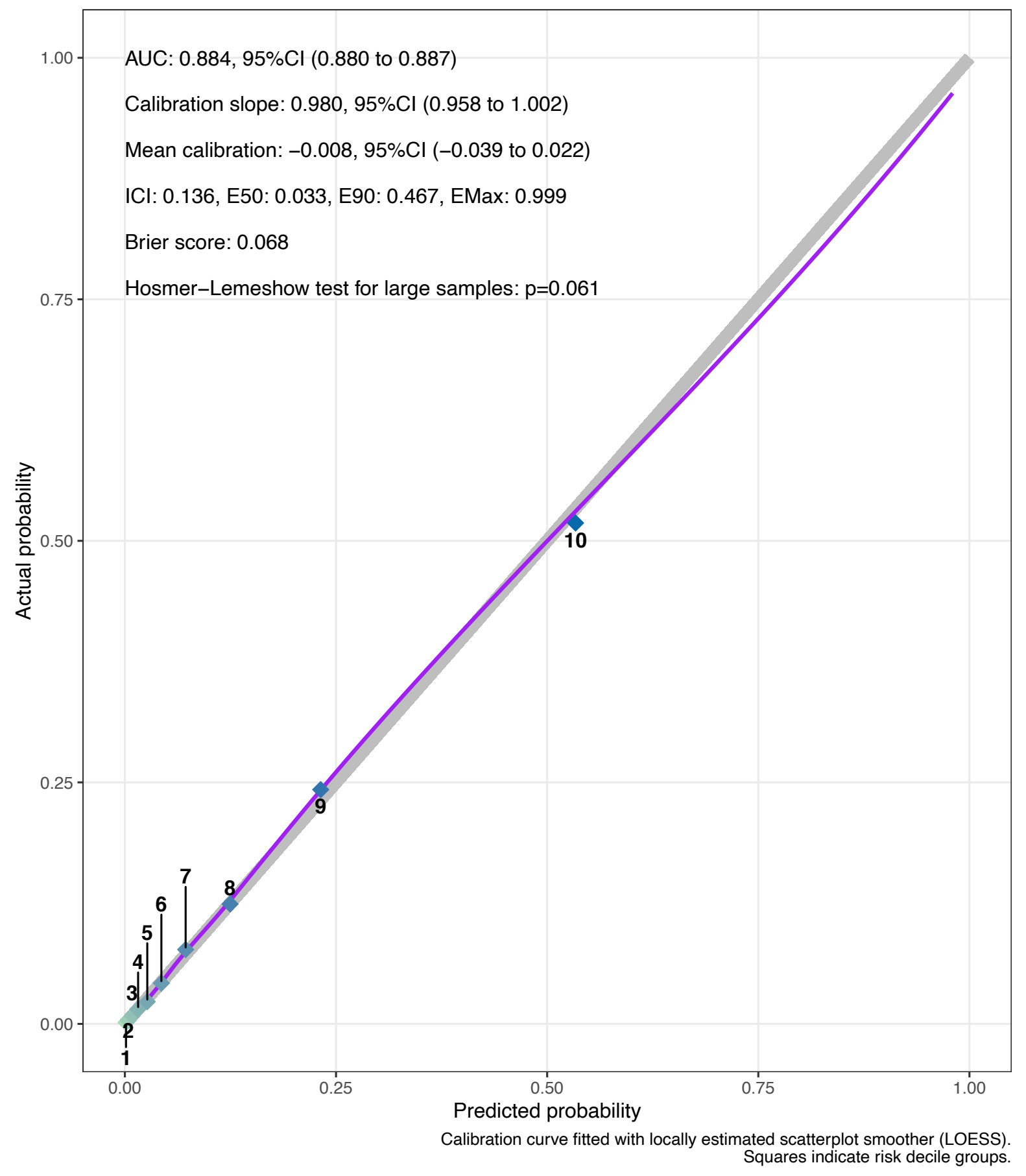


Supplemental Figure 8: Geographic transportability: AUC random effects meta-analysis.

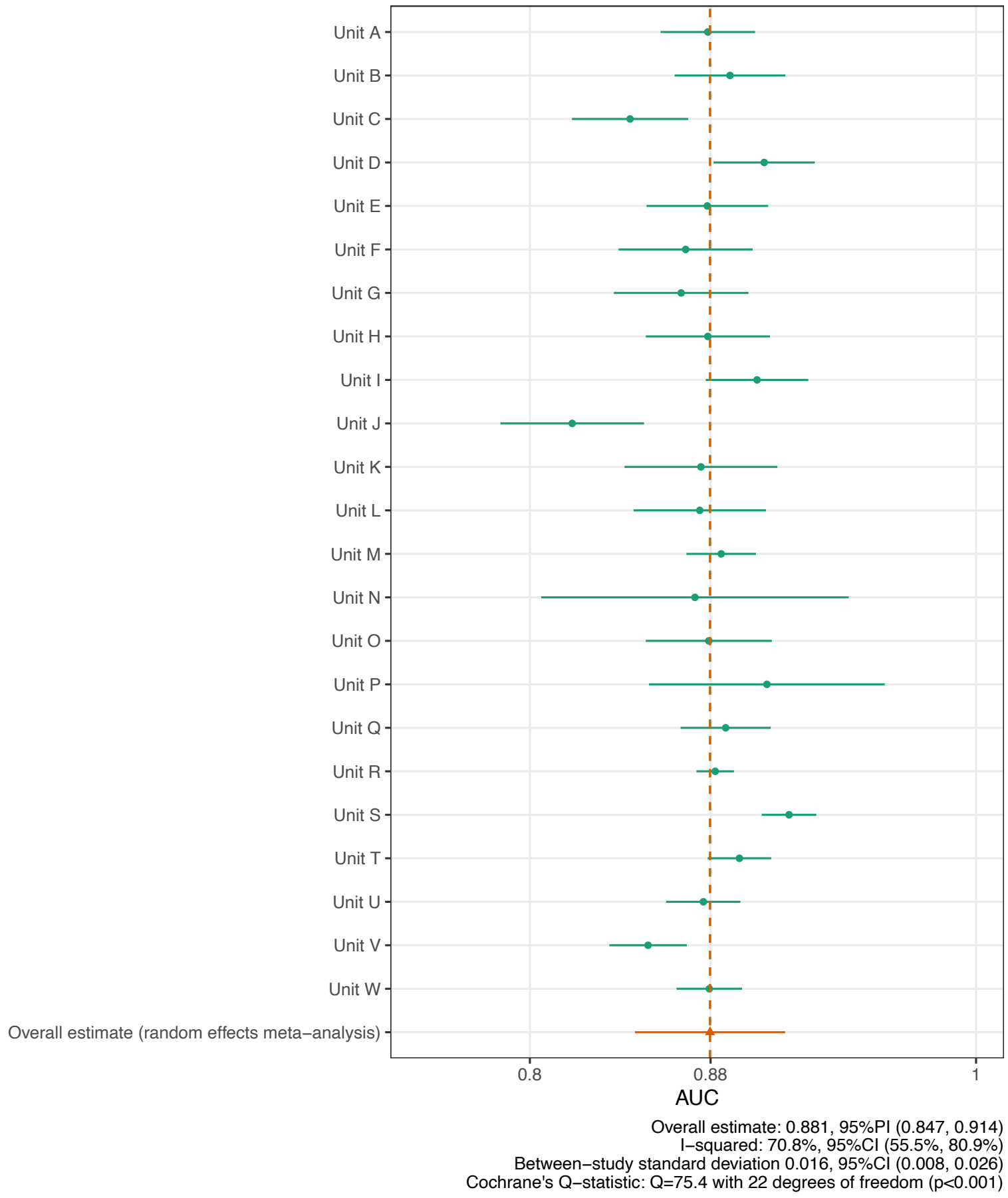


Supplemental Figure 9: Geographic transportability: Mean calibration random effects meta-analysis.

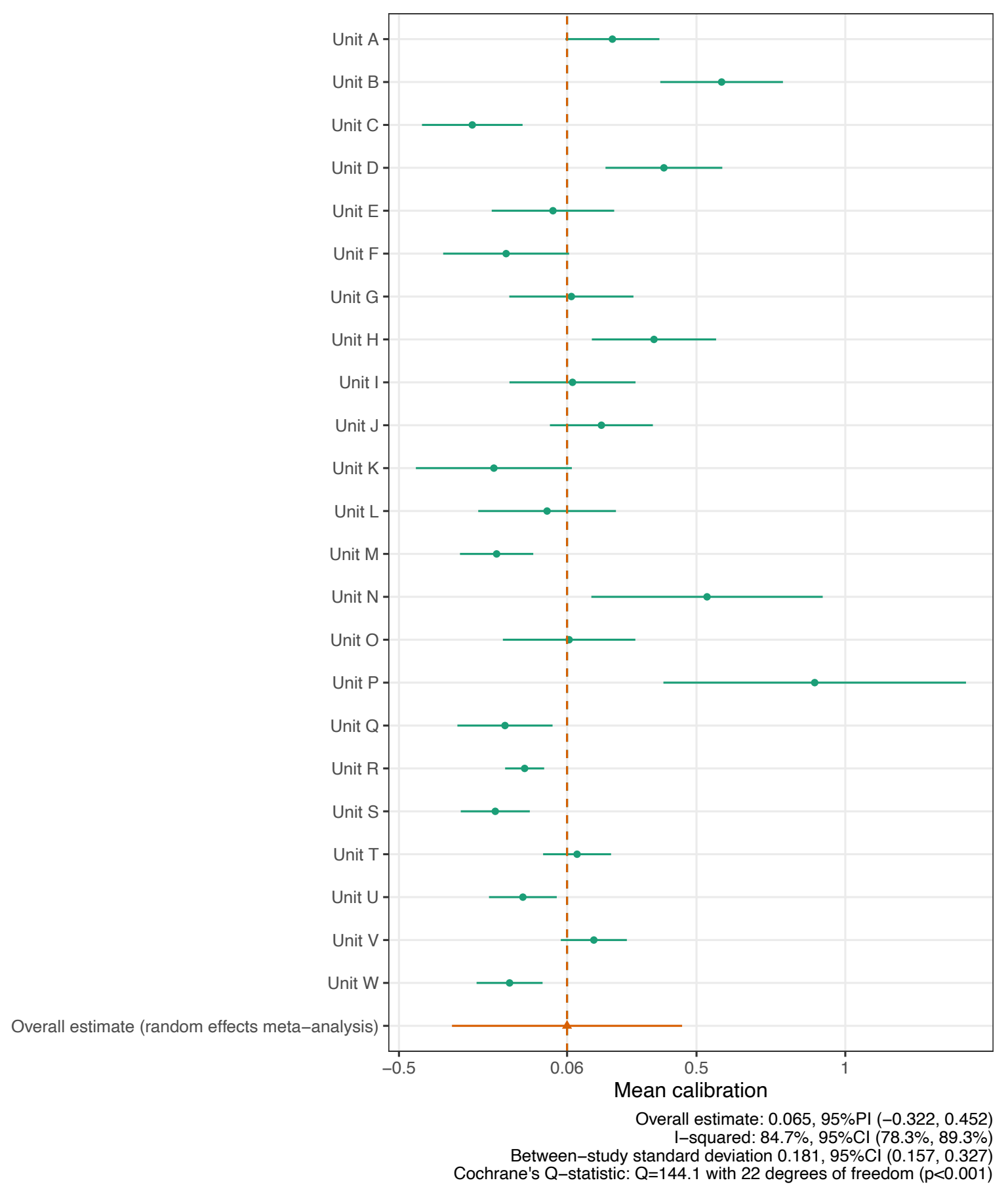


Supplemental Figure 10: Geographic transportability: Calibration slope random effects meta-analysis.

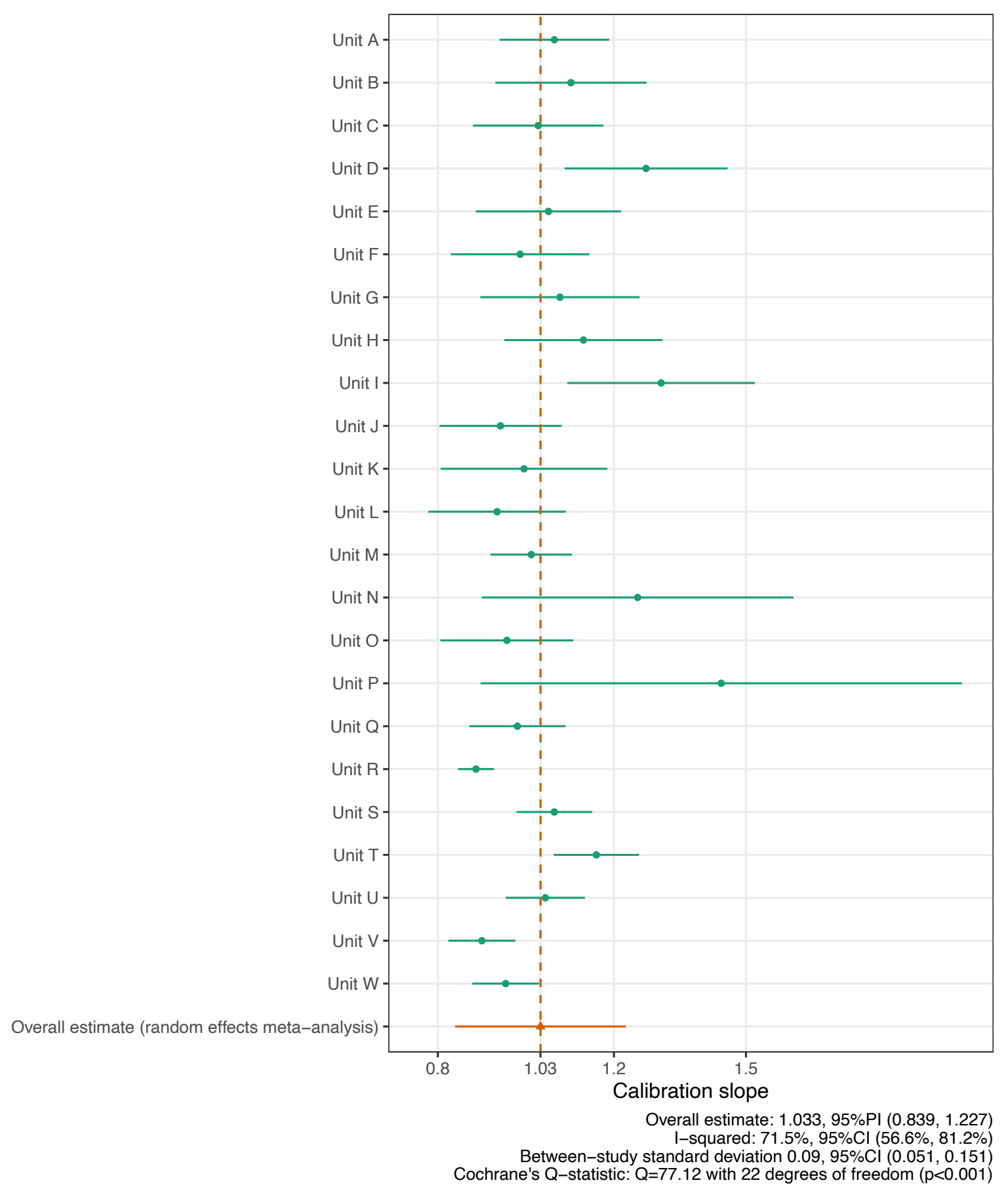


Supplemental Figure 11: Temporal transportability: Pooled estimates.

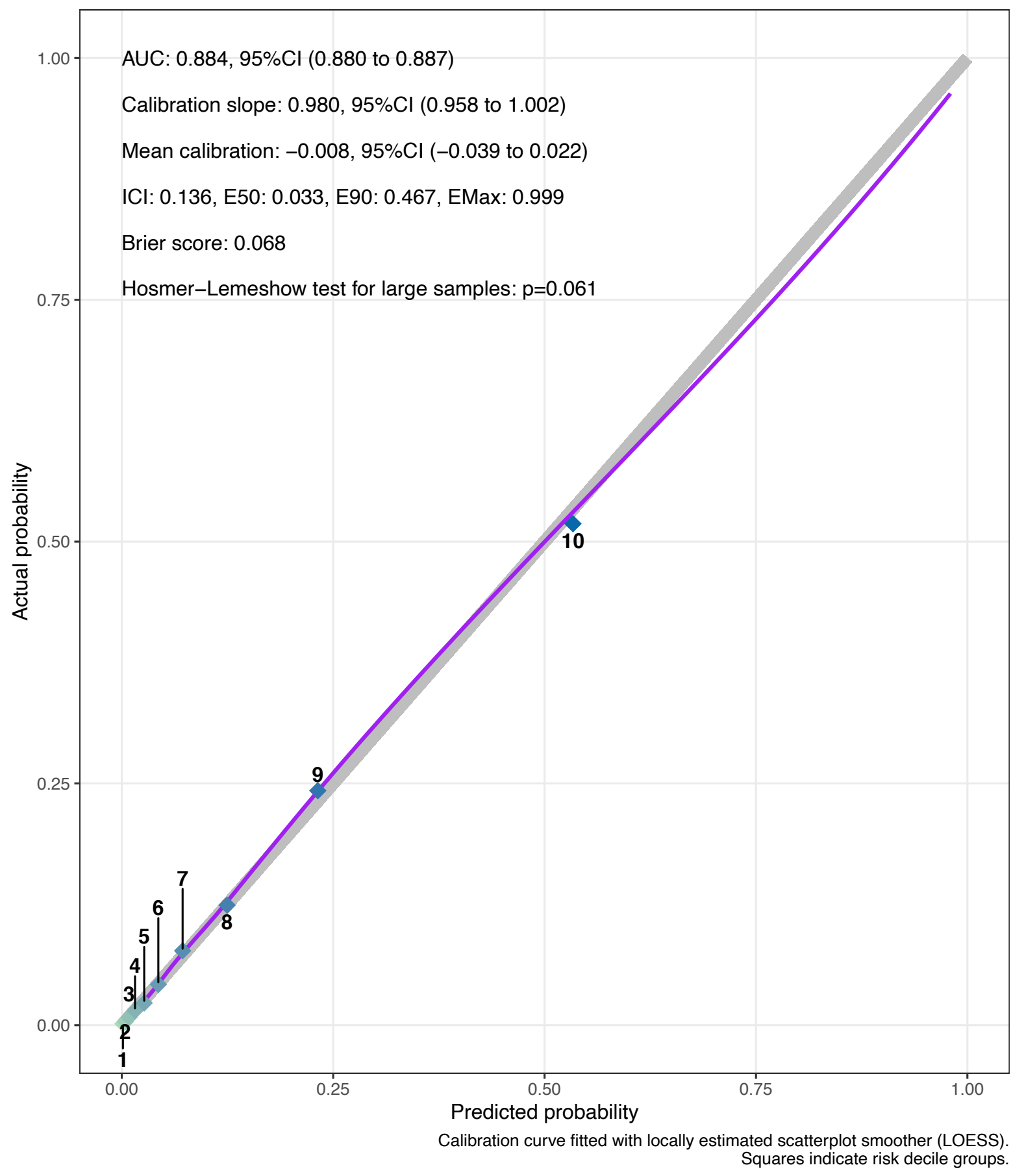


Supplemental Figure 12: Geographic-temporal transportability: Pooled estimates.

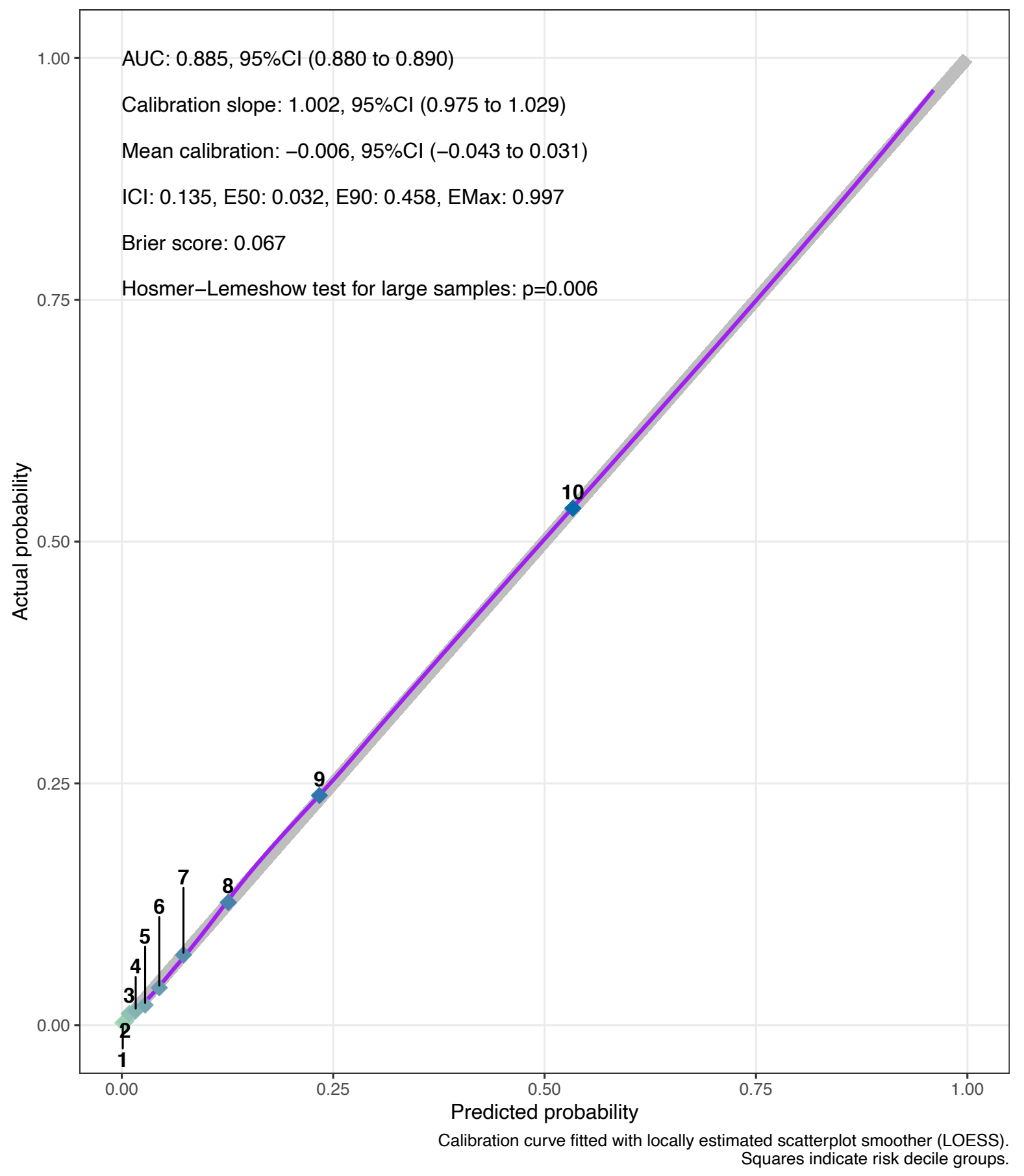


Supplemental Figure 13: Geographic-temporal transportability: AUC random effects metaanalysis.

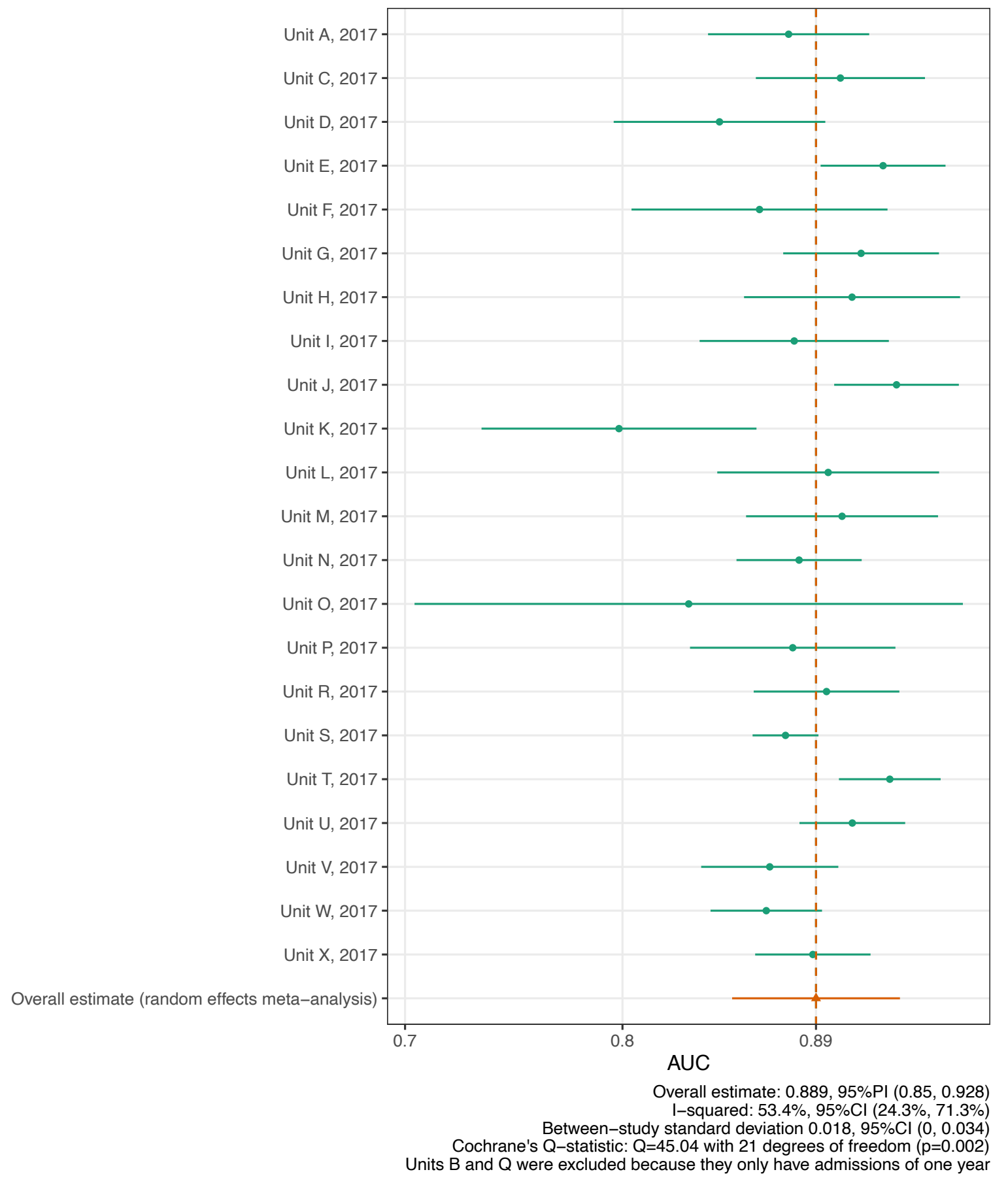


Supplemental Figure 14: Geographic-temporal transportability: Mean calibration random effects meta-analysis.

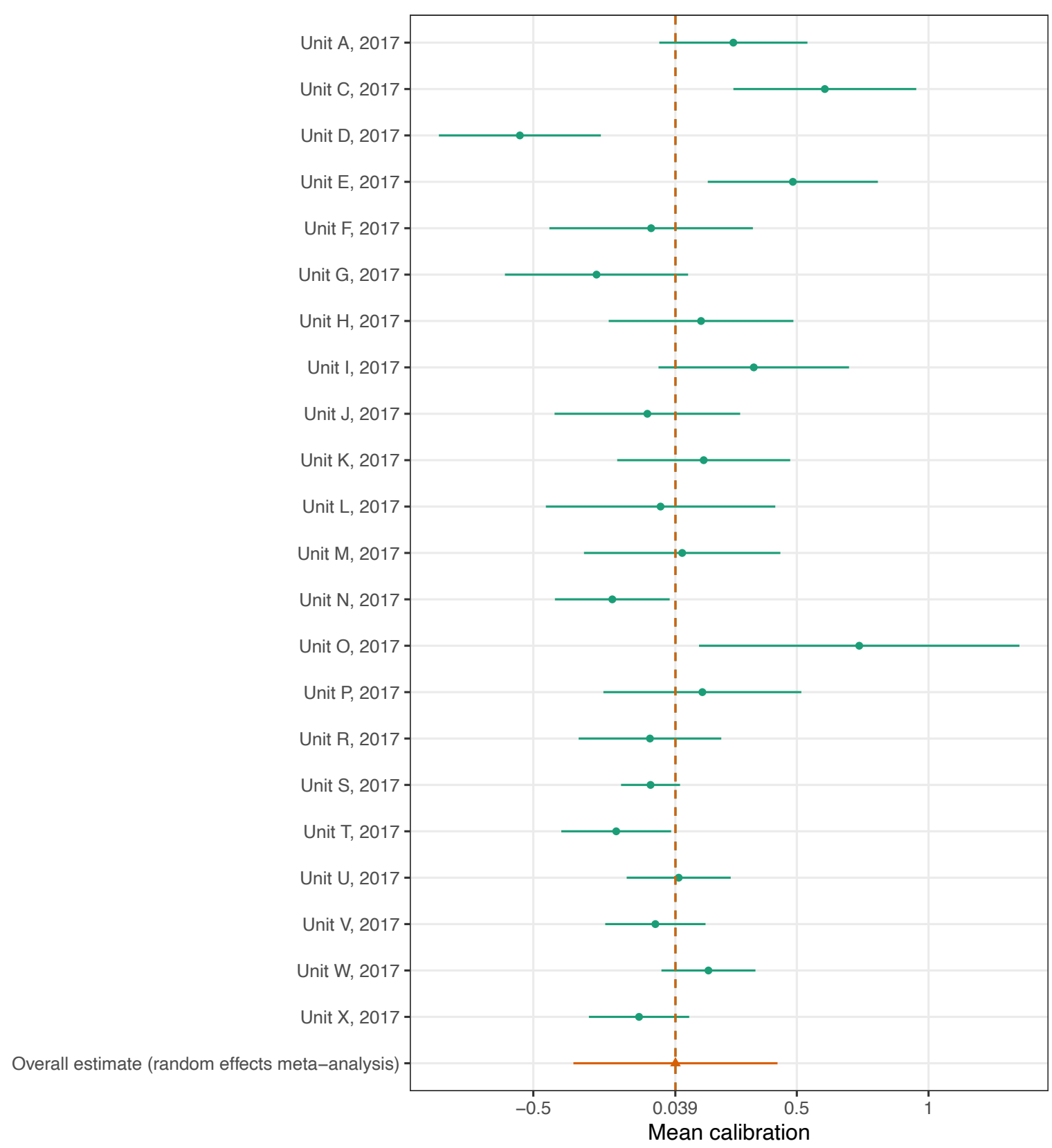

Overall estimate: $0.039,95 \% \mathrm{PI}(-0.348,0.427)$ I-squared: $65.8 \%, 95 \% \mathrm{Cl}(46.4 \%, 78.2 \%)$ Between-study standard deviation $0.179,95 \% \mathrm{Cl}(0.132,0.341)$ Cochrane's $Q$-statistic: $Q=61.44$ with 21 degrees of freedom $(p<0.001)$ Units $B$ and $Q$ were excluded because they only have admissions of one year 
Supplemental Figure 15: Geographic-temporal transportability: Calibration slope random effects meta-analysis.

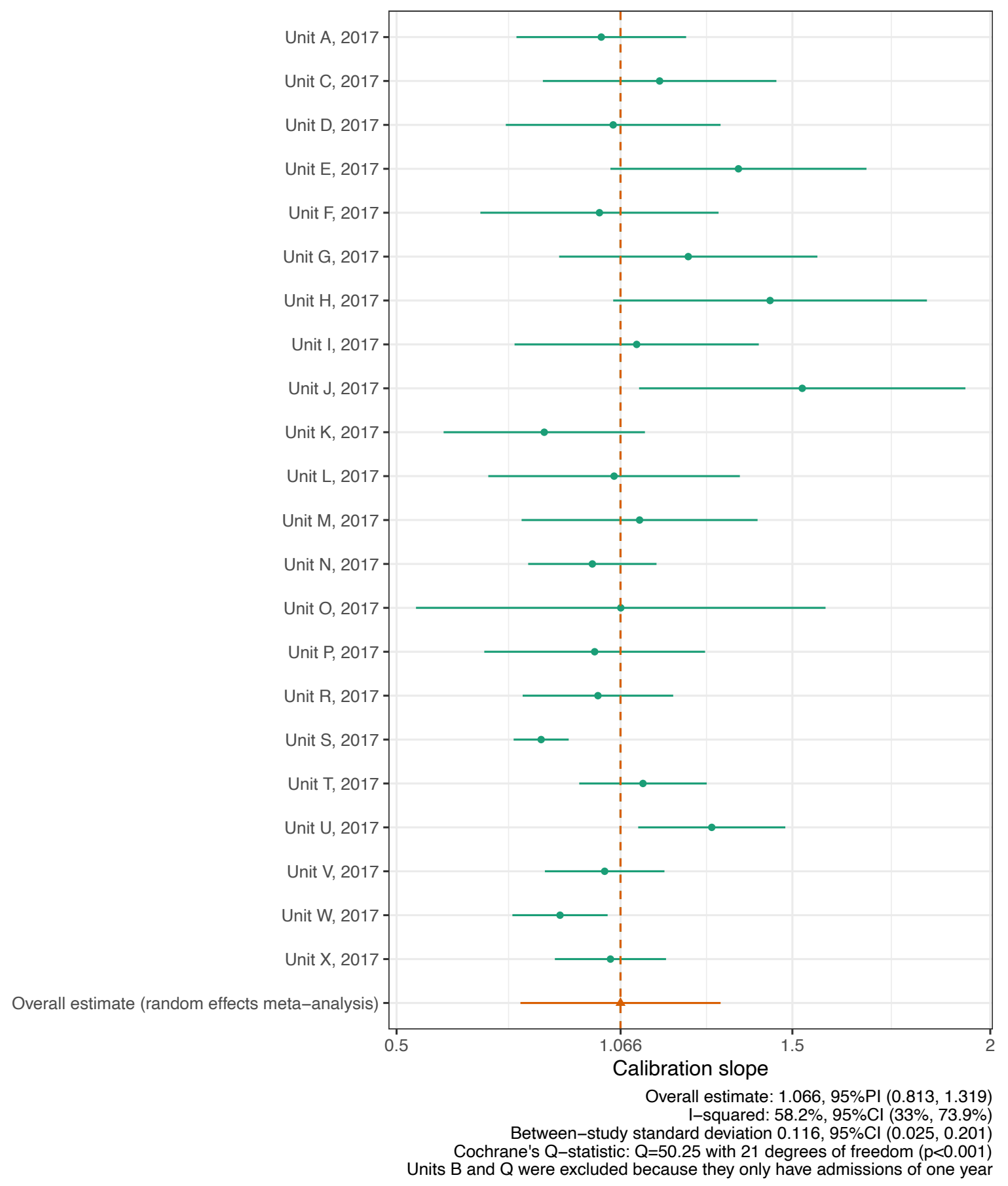


Supplemental Figure 16: Effect estimates of categorical variables from different sensitivity models.

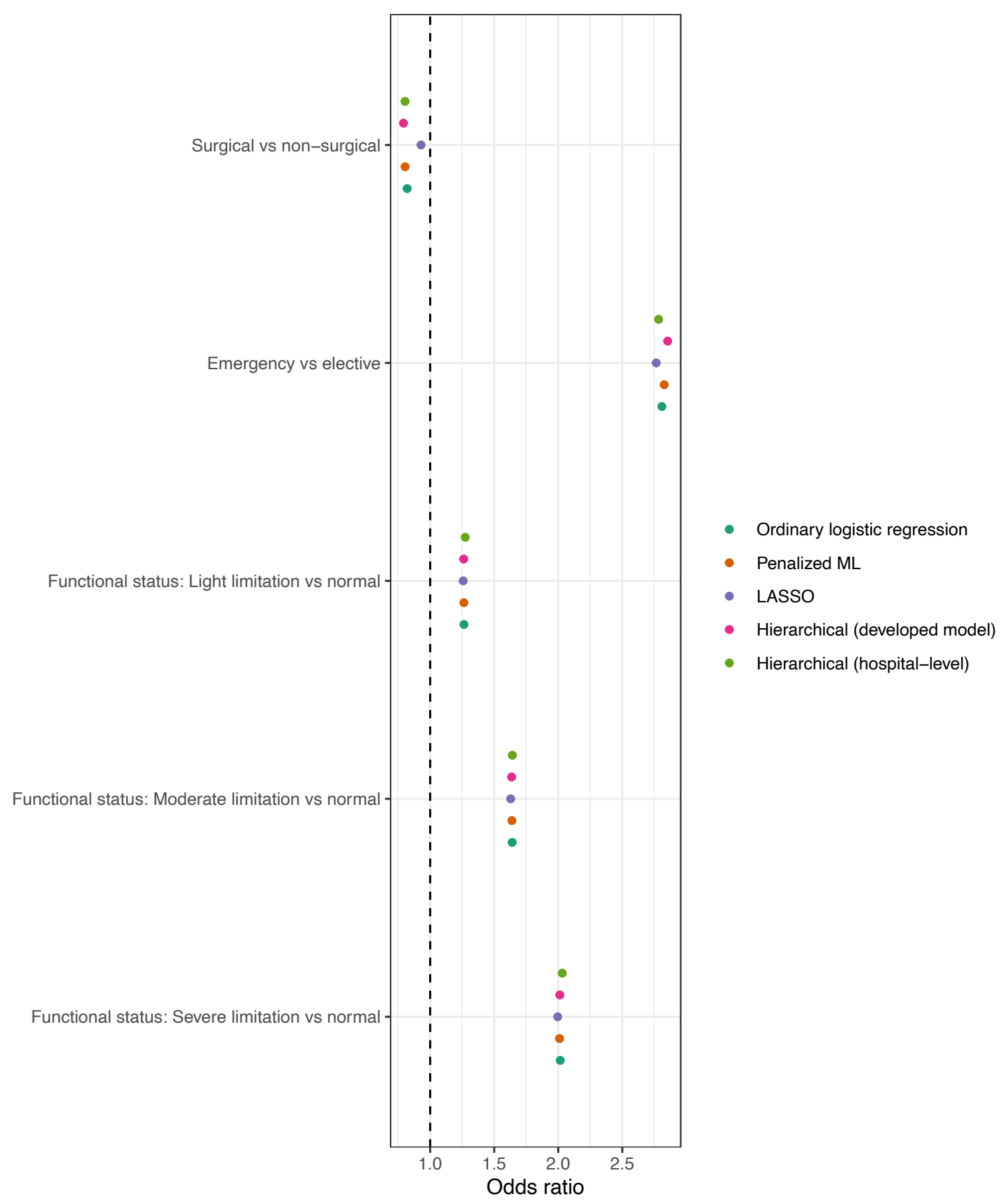


Supplemental Figure 17: Effect estimates of age and the modified SAPS-II score from different sensitivity models.

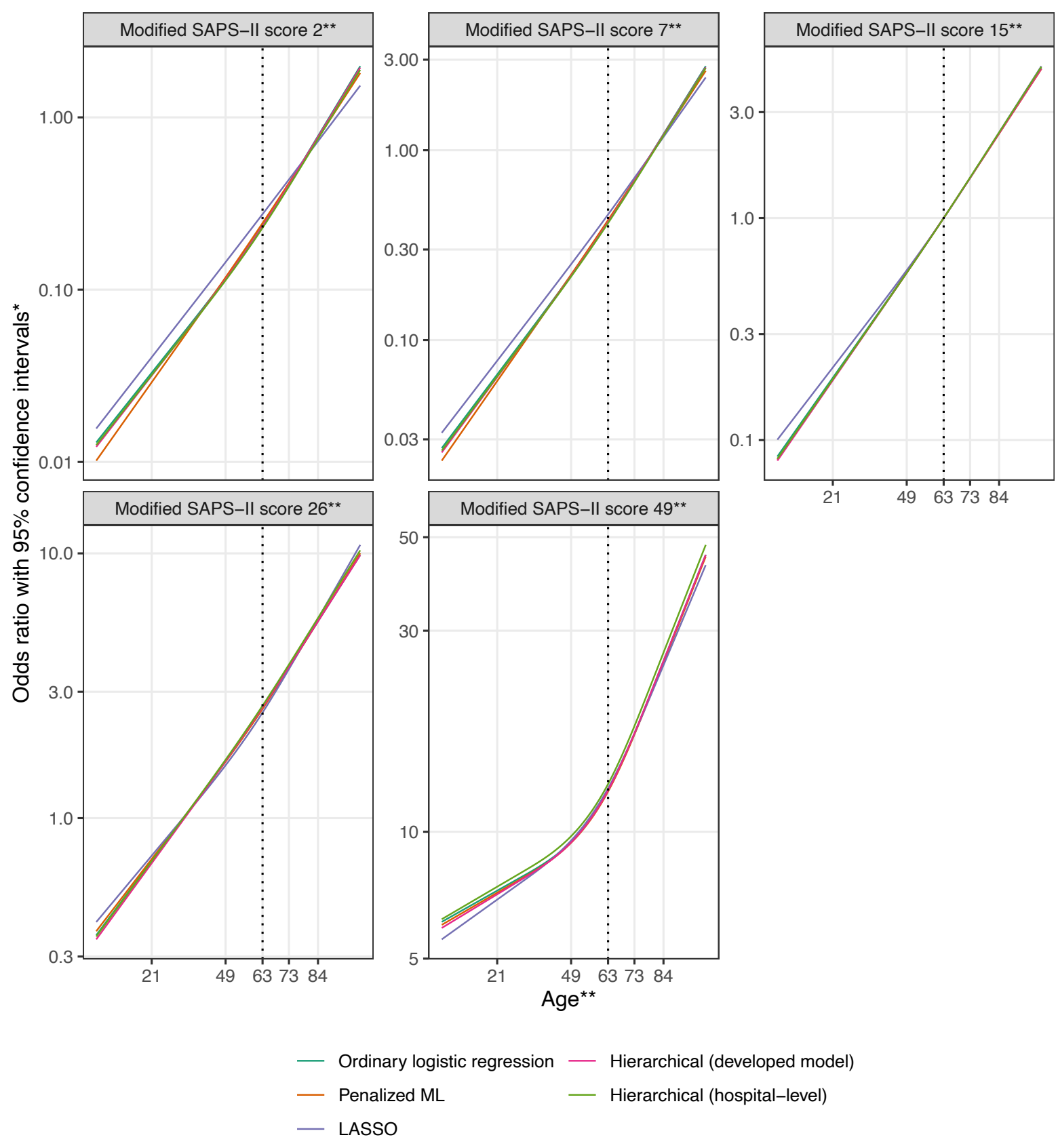

* Reference is median age (63 years) and median modified SAPS-II score (15 points). Estimates adjusted for admission type (non-surgical, elective) and normal functional status. ** Values chosen based on 5th, 25th, 50th, 75th, 95th population percentiles. 
Supplemental Figure 18: Discrimination and calibration properties of the developed risk when the varying estimates of APACHE-III diagnoses are not set to zero.

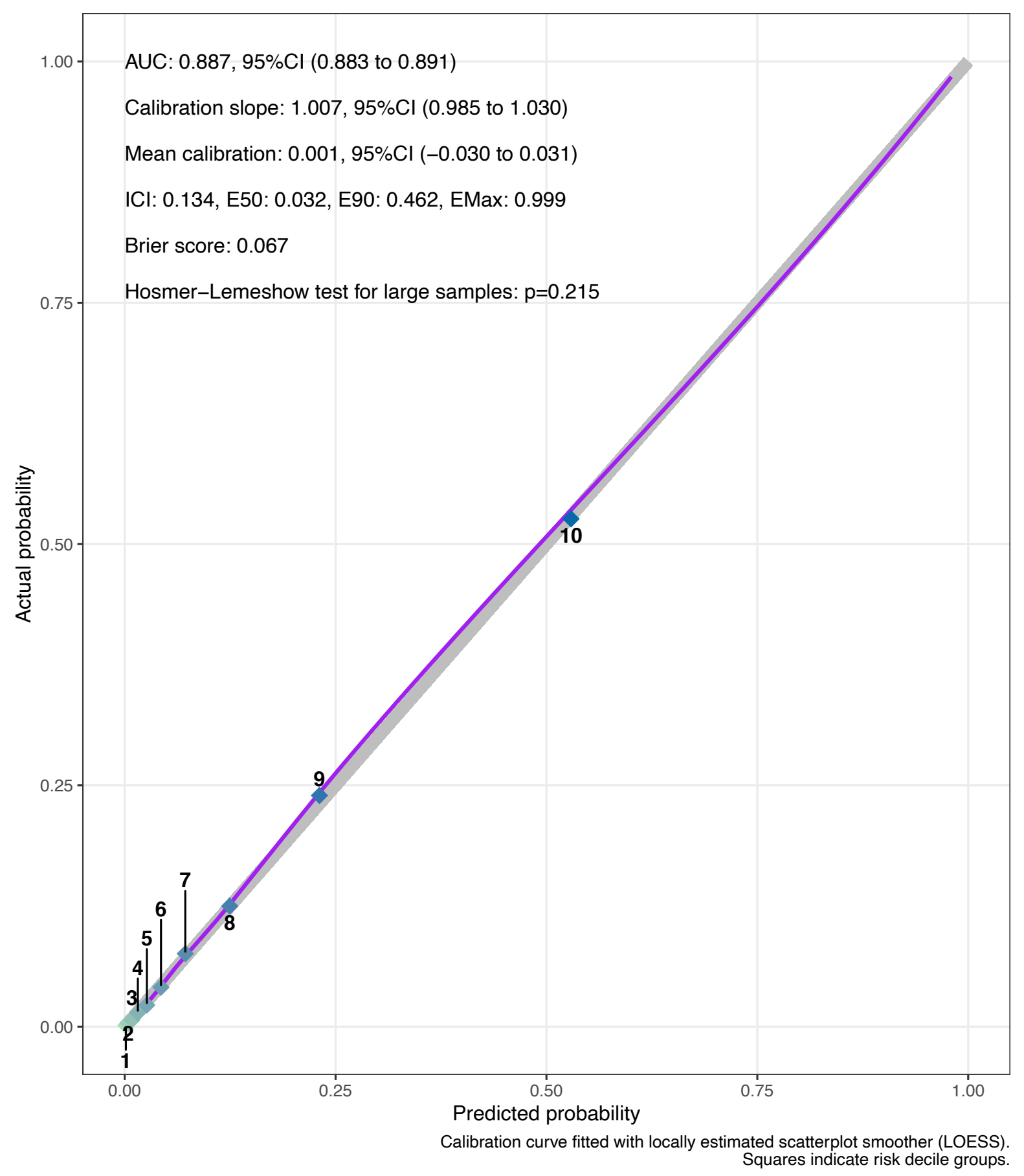

